\title{
Edible Coating for Shelf-Life Extension of Fresh Banana Fruit Based on Gamma Irradiated Plasticized Poly(vinyl alcohol)/Carboxymethyl Cellulose/Tannin Composites
}

\author{
Magdy M. H. Senna ${ }^{1}$, Khalid M. Al-Shamrani2 ${ }^{2}$ Abdullah S. Al-Arifi ${ }^{3}$ \\ ${ }^{1}$ Radiation Chemistry Department, National Center for Radiation Research and Technology, Cairo, Egypt \\ ${ }^{2}$ Petrochemicals Research Institute, King Abdulaziz City for Science and Technology, Riyadh, KSA \\ ${ }^{3}$ Chemistry Department, Faculty of Science, King Saud University, Riyadh, KSA \\ Email: magdysenna@hotmail.com
}

Received 13 March 2014; revised 17 April 2014; accepted 30 April 2014

Copyright (C) 2014 by authors and Scientific Research Publishing Inc.

This work is licensed under the Creative Commons Attribution International License (CC BY).

http://creativecommons.org/licenses/by/4.0/

(c) (i) Open Access

\begin{abstract}
The interest in the development of edible and biodegradable films has increased because it is every day more evident that non-degradable materials are doing much damage to the environment. Blends based on different ratios of plasticized poly(vinyl alcohol) (PVA), carboxymethyl cellulose (CMC) and Tannin compound were prepared by solution casting in the form of thin films. Then the blend films were exposed to different doses of gamma radiation. First, the effect of gamma irradiation and the Tannin compound, as an antimicrobial agent, on the thermal and mechanical properties was investigated. As an application in the field of the prolongation of food preservation lifetime, banana fruits were coated with solutions of gamma irradiated PVA/CMC blends in the presence of Tannin. The results showed that the gamma irradiation improved the thermal properties, which provides suitable materials based on natural biodegradable polymers for food preservation withstanding the temperature and stresses.
\end{abstract}

\section{Keywords}

Biodegradable Films, Poly(vinyl alcohol), Carboxymethyl Cellulose, Gamma Irradiation, Food Coating

\footnotetext{
${ }^{*}$ Corresponding author.
} 


\section{Introduction}

The increasing demand for fresh fruits and vegetables forces the food industry to develop new and better methods for maintaining food quality and extending shelf life. On the other hand, consumers around the world demand food of high quality, without chemical preservatives and with extended shelf life. An increased effort has been made to discover new natural preservatives and antimicrobials. This is because fruits are directly sold for consumption. For the consumers, the most important attributes of fresh fruits are flavor and appearance, as well as their safety and nutritional value [1]. The application of edible films and coatings to food products represents a new approach to solve this problem. Edible films and coatings can include antioxidant and antimicrobial agents in their formulation, which results in a better preservation of quality [2].

Recently, edible coatings have been widely studied for preservation of fruits and vegetables. There is increasing public interest in development of edible natural biodegradable coatings to replace the currently used commercial synthetic waxes for maintaining postharvest quality of fruit. In this regard, developed polysaccharide-based edible bilayer coating comprises carboxymethyl cellulose (CMC) and chitosan in preserving postharvest quality of various citrus fruit, including "Or" and "Mor" mandarins, "Navel" oranges, and "Star Ruby" grapefruit after simulated storage and marketing have been studied [3]. It was found that the CMC/chitosan bilayer coating was equally effective as the commercial polyethylene wax in enhancing fruit gloss. Furthermore, the $\mathrm{CMC} /$ chitosan bilayer coating slightly increased fruit firmness, especially of oranges and grapefruit, but was mostly not effective in preventing post-storage weight loss. The effects of different concentrations of lemongrass essential oil incorporated into an alginate-based [sodium alginate $1.29 \%(\mathrm{w} / \mathrm{v})$, glycerol $1.16 \%(\mathrm{w} / \mathrm{v})$ and sunflower oil $0.025 \%(\mathrm{w} / \mathrm{v})$ ] edible coating on the respiration rate, physico-chemical properties, and microbiological and sensory quality of fresh-cut pineapple during 16 days of storage were evaluated [4]. The results showed that yeast and mould counts and total plate counts of coated samples containing $0.3 \%$ and $0.5 \%(\mathrm{w} / \mathrm{v})$ lemongrass were lower than other samples. The quality and shelf-life of strawberries with edible coatings based on carboxymethyl cellulose (CMC), hydroxypropylmethyl cellulose (HPMC) and composites with chitosan (CH) coatings on the shelf-life and overall quality of strawberry fruit were studied [5]. Fruit coated with edible coatings showed significant delays in the change of weight loss, decay percentage, titratable acidity, $\mathrm{pH}$, total soluble solids and ascorbic acid content as compared to uncoated control fruit. The optimal composition of edible coatings in view of their application to extend the shelf life of several tropical fruits was studied [6]. Coatings constituted by galactomannans from different sources (Caesalpinia pulcherrima and Adenanthera pavonina) and glycerol were characterized as coatings for five tropical fruits: acerola (Malpighia emarginata), caja (Spondias lutea), mango (Mangifera indica), pitanga (Eugenia uniflora) and seriguela (Spondias purpurea). The surface properties of the five fruits were determined and different aqueous galactomannan solutions $(0.5 \%, 1.0 \%$ and $1.5 \%)$ with glycerol $(1.0 \%, 1.5 \%$ and $2.0 \%)$ were tested for their wettability on fruits. The application of coatings in fruits such as apples [7], mango [8]-[10] and kiwi [11] was also studied.

It was established that radiation crosslinking of polymers improves the thermal, mechanical properties and it can be induces reactive compatibilization in polymer blends [12] [13]. The main advantages of the application of high-energy irradiation to polymer blends are the formation of strong bonds between macromolecules. Compatibilization of polymer blends by high-energy radiation can be achieved without addition of any ionomer, and in presence of multifunction monomers and ionomers, they are effective in accelerating and increasing the crosslinking degree [14].

Carboxymethyl cellulose (CMC) polymer has a significant swelling capacity, non-toxicity, biodegradability, unique reactivation, hydrophilicity and molecular characteristics [15]. Cellulose and its derivatives generally undergo degradation by high energy radiation. Radiation crosslinking, however, was observed in high concentration solution of CMC [16]. The development of environmental friendly materials is a continuing area of challenge for food packaging and coating technology. One of these synthetic materials is poly(vinyl alcohol). This polymer has excellent chemical resistance, also its optical and physical properties enable a broad industrial uses. In addition, it was reported that PVA is a biodegradable polymer, in which the mechanism of biodegradation involves first dehydrogenation into the corresponding carbonyl groups to form $\beta$-hydroxy ketone which followed by aldolase-type cleavage [17].

Tannin has attracted the interest due to their chemical activities, such as anti-inflammatory, antibacterial, antiseptic and antimicrobial. Some of these properties already exhibit scientifically validated activity. Besides the use in folk medicine as an anti-inflammatory, healing and anti-hemorrhagic to treat venereal and stomach diseases, recent studies have shown that tannins can be used as feedstock for the production of adhesives, due to the reactivity of their condensed tannins present in the bark and leaves. Then, there is the interest to use the tannins 
for multi-purpose applications, since it is a natural material with a renewable character [18].

Bananas are one of the most popular fruits worldwide and particularly in Egypt that are characterized with unique and highly desirable taste and flavor. In the present work, we have proposed to study the possibility to obtain blend materials starting from PVA and CMC in order to improve the physico-chemical properties of the blends. The effect of Tannin and different irradiation doses on the structure and properties of PVA/CMC/Tannin composite films were investigated. Also, these blends may eventually used in film industry as edible packaging material for food preservation. The second goal was to evaluate the quality of coated Banana at ambient temperature instead of refrigerated storage. Non-coated fruits and fruits coated with gamma irradiated PVA/CMC composite films were compared.

\section{Experimental}

\subsection{Materials}

Poly(vinyl alcohol) (PVA) was a laboratory-grade chemical and purchased from Backer Chemical Co., USA. It was in the form of powder, fully hydrolyzed and has an average molecular weight of $125,000 \mathrm{~g} / \mathrm{mol}$. Laboratory-grade chemical Carboxymethyl cellulose (CMC) with viscosity at $20^{\circ} \mathrm{C}$ of $1500 \mathrm{cp}$ was purchased from El Gomhoria Co., Cairo, Egypt. Tannin (TA) was obtained from Riedel-DeHaen Co., Germany, and was used without further purification. The chemical structure of TA is shown Scheme 1.

\subsection{Preparation of PVA/CMC Blends}

The required amounts of $\mathrm{CMC}$ were added to $100 \mathrm{ml}$ of distilled water at room temperature with continuous stirring. After, CMC was completely suspended; the temperature was gradually raised to $95^{\circ} \mathrm{C}$ with continuous stirring. During the stirring, the required amount of PVA dissolved in hot water was added to CMC solution. The mixture was poured on Petri dishes and dried for $48 \mathrm{~h}$ at $37^{\circ} \mathrm{C}$ to form films. Complete drying was avoided, as some moisture is required for films to remain flexible and not to crack. The films were finally removed from the dishes and placed in sealed containers at $4^{\circ} \mathrm{C}$ to avoid moisture exchange.

\subsection{Gamma Irradiation}

Irradiation to the required doses was carried out in the cobalt-60 gamma cell, (Canada) at a dose rate of 5.87 $\mathrm{kGyh}^{-1}$ in air. This source was installed at the King Abdul-Aziz City for science and technology (KACST).

\subsection{Thermogravimetric Analysis (TGA)}

TGA thermograms were obtained using Mettler Toledo TGA-1), USA with a heating rate of $10^{\circ} \mathrm{C} / \mathrm{min}$ under flowing nitrogen $(20 \mathrm{ml} / \mathrm{min})$ from room temperature to $500^{\circ} \mathrm{C}$.

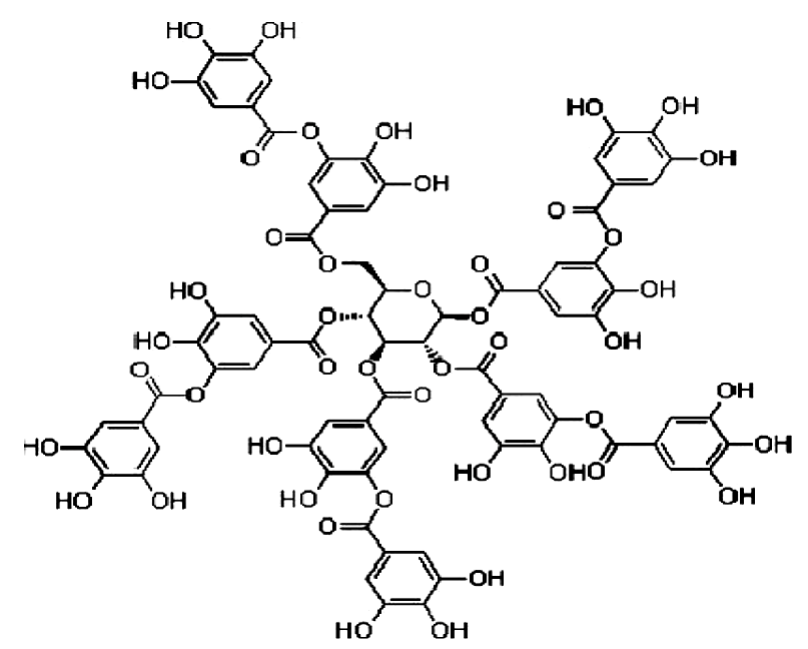

Scheme 1. Chemical structure of Tannin (TA) containing a macromolecular aromatic ester with two or three $-\mathrm{OH}$ groups. 


\subsection{Differential Scanning Calorimetry (DSC)}

DSC measurements were performed using a differential scanning calorimeter (DSC-60) Shimadzu, Japan, in sealed pans. A heating rate of $10^{\circ} \mathrm{C} / \mathrm{min}$ was utilizing under nitrogen atmosphere over the temperature range from room temperature to $350^{\circ} \mathrm{C}$.

\subsection{Mechanical Properties}

Dynamic mechanical properties of PVA/CMC blends were determined using dynamic mechanical thermal analyzer (PerkinElmer (USA). The mechanical properties of the samples were tested in the form of strips of $4 \mathrm{~cm}$ in length and $0.4 \mathrm{~cm}$ in width. The tension-torsion mode was used under the test temperature range from room temperature to $200^{\circ} \mathrm{C}$ with a heating rate of $3{ }^{\circ} \mathrm{C} / \mathrm{min}$ and a constant strain amplitude of $0.5 \%$. Storage modulus $\left(E^{\prime}\right)$ loss modulus $\left(E^{\prime \prime}\right)$ and loss tangent $(\tan \delta)$ of each sample were recorded at frequency mode $1 \mathrm{~Hz}$.

\subsection{Application of PVA/CMC/TA as Surface Coating Food Preservation}

During the stirring of the solutions of PVA/CMC, the required amount of dissolved TA is added. The blend solutions were gamma irradiated to different doses. The PVA/CMC solutions were applied to the banana fruit (carefully washed and dried) by surface coating in such a way that the surfaces are completely covered by the solutions. The coated samples with blend solutions were compared with the uncoated samples. All the banana samples were stored at room temperature for 19 days.

\section{Results and Discussion}

\subsection{Characterization of PVA/CMC Blends}

\subsubsection{Thermogravimetric Analysis (TGA)}

Thermal characterization is a well-known method for determining the miscibility of polymers blends [19]. The thermal stability of any polymeric materials is mainly dependent on the covalent bonds between the atoms forming polymer chains. The reported bond dissociation energy values for $\mathrm{C}-\mathrm{H}, \mathrm{C}-\mathrm{C}, \mathrm{C}-\mathrm{O}, \mathrm{O}-\mathrm{H}$ and $\mathrm{C}=\mathrm{C}$ was 414, 347, 351, 464 and $611 \mathrm{~kJ} / \mathrm{mol}$ [20]. According to these values, the average dissociation energy for PVA and CMC were calculated to be 419 and $578 \mathrm{~kJ} / \mathrm{mol}$, respectively. According to these values, it may expect that addition of CMC to PVA will increase the thermal stability of the polymer blends. Thermogravimetric analysis (TGA) is widely used method to investigate the thermal stability of polymers over a wide range of temperatures.

\subsubsection{Effect of Blend Composition}

Figures 1-3 show the TGA thermograms and the corresponding rate of thermal decomposition reaction for PVA/CMC blends, before and after they had been gamma irradiated to different doses. It can be seen that the decomposition was started early at temperature range of $\left(100^{\circ} \mathrm{C}-200^{\circ} \mathrm{C}\right.$ with loss percentage of $(3 \%-10 \%)$ of the sample weight depending on the blend composition. This loss in sample was related to water removal during this range and the loss in $\mathrm{CMC}$ and PVA/CMC blends was more than pure PVA. This may be due to that CMC can accommodate more water molecules between its chains than PVA molecules. With progress in thermal heating a more decomposition was occurred, in the temperature range $\left(300^{\circ} \mathrm{C}-500^{\circ} \mathrm{C}\right)$. In this rang the weight loss was $(15 \%-90 \%)$ depending on the PVA/CMC ratio and it can be seen that the thermal stability of CMC and PVA/CMC blend was lower than pure PVA. On the other hand, the rate of thermal decomposition reaction curves for PVA/CMC displayed similar trends and goes through one maximum indicating good distribution and compatibility between PVA and CMC blends. Visual observation also showed that all the solutions of PVA/CMC mixture were clear at room temperature. The temperatures of maximum value $\left(\mathrm{T}_{\max }\right)$ were found $\left(365^{\circ} \mathrm{C}-325^{\circ} \mathrm{C}\right)$ depending on the blend composition. A little decrease $\left(\mathrm{T}_{\max }\right)$ was found with increasing the $\mathrm{CMC}$ ratio in the blend.

As shown in Figures 1-3 and Table 1, the effect of irradiation dose on thermal stability depends on the ratio of CMC. Irradiation of PVA/CMC blends to a dose of (20 kGy) improved the thermal stability of these blends; this improvement was more in case of blends containing higher percentage of PVA. The decrease in thermal stability in CMC may attribute to presence of glycoside bond that easily dissociated with irradiation. Increasing irradiation dose (40 kGy) decreased the thermal stability of the polymer blends, Radoslaw found that irradiation of CMC induces radical formation at different positions [21]. 

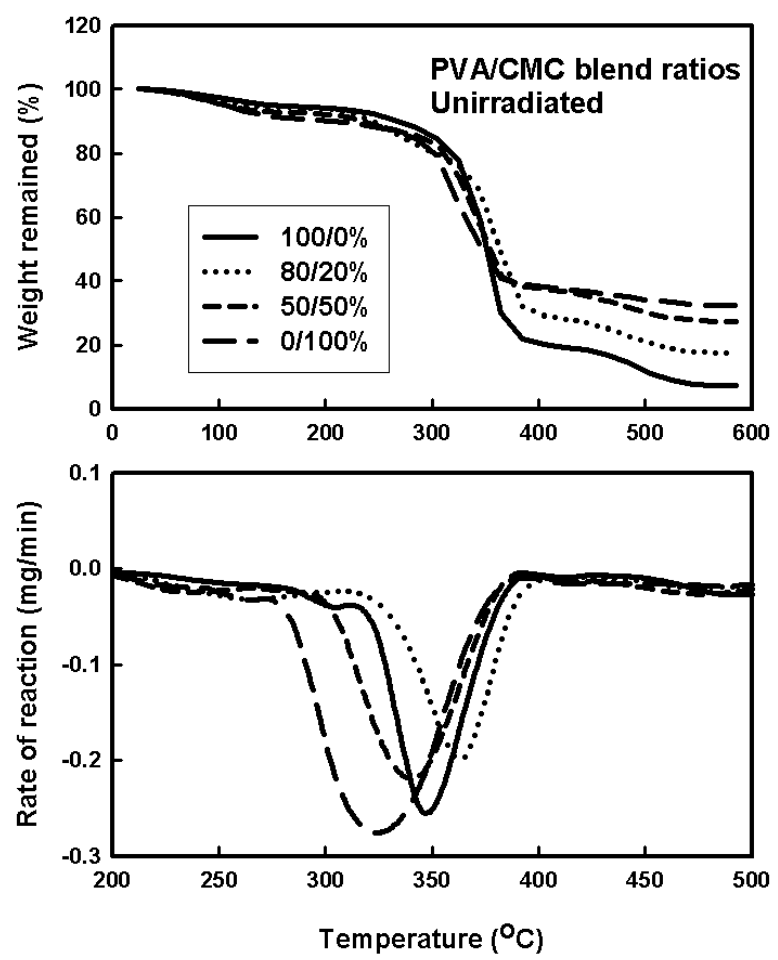

Figure 1. TGA thermograms and the rate of thermal decomposition reaction of unirradiated $\mathrm{PVA} / \mathrm{CMC}$ blend of different compositions.
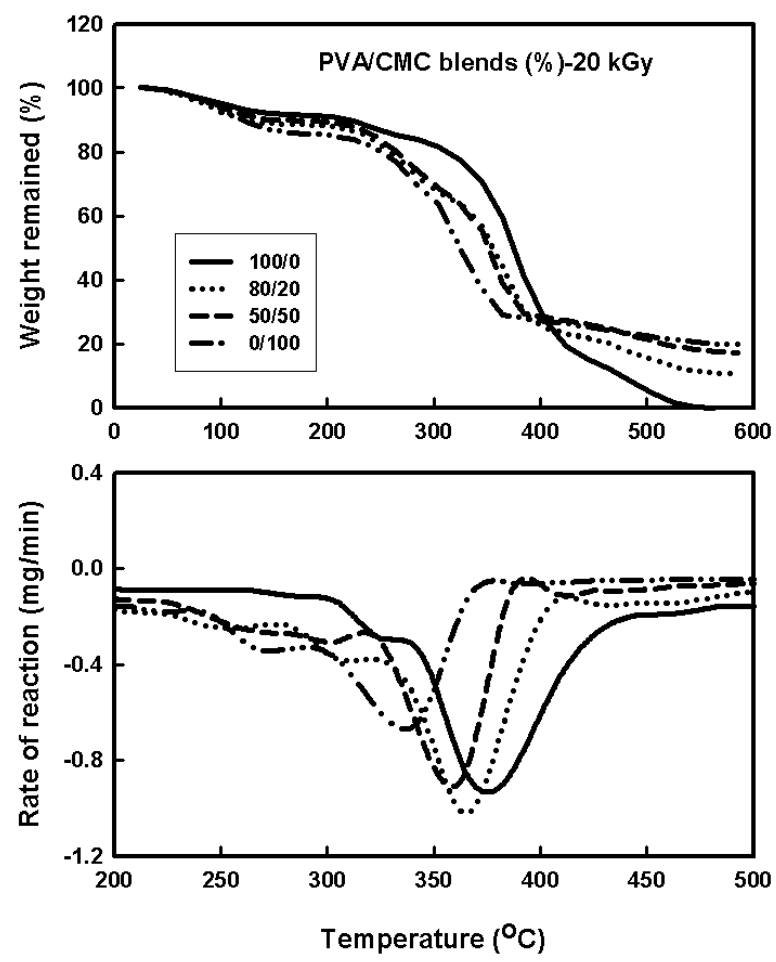

Figure 2. TGA thermograms and the rate of thermal decomposition reaction of different compositions of gamma irradiated PVA/CMC blends to a dose of $20 \mathrm{kGy}$. 

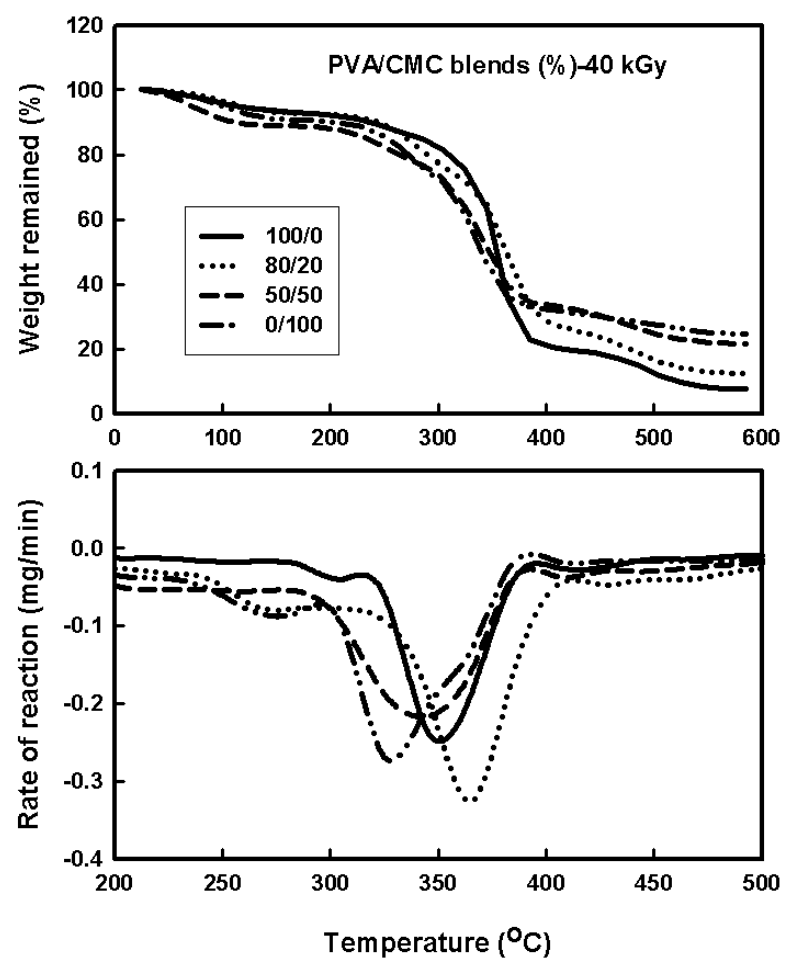

Figure 3. TGA thermograms and the rate of thermal decomposition reaction of different compositions of gamma irradiated PVA/CMC blends to a dose of $40 \mathrm{kGy}$.

\subsubsection{Effect of Tannin (TA) Compound}

The TGA thermograms and the corresponding rate of thermal decomposition reaction for blends and containing a constant ratio (5\%) of TA compound, gamma irradiated to different doses are shown in Figure 4 and Figure 5. From these figures it can be seen that the addition of TA to CMC/PVA improved the thermal stability. On the other hand, this improvement was decreased in case of CMC than the improvement in the PVA and consequently their blends. From the Figures, it can be seen also that the curves had similar trend where the thermal decomposition for pure PVA went through one maximum. On the other hand, the rate of thermal decomposition reaction curves for PVA blends in presence of TA polymer displayed similar trends as that not containing TA. The temperatures of maximum value $\left(\mathrm{T}_{\max }\right)$ were found $\left(320^{\circ} \mathrm{C}-402^{\circ} \mathrm{C}\right)$ depending on the blend composition-see Table 2 a decrease in $\left(\mathrm{T}_{\max }\right)$ were found with increase the $\mathrm{CMC}$ ratio in the blend.

The effect of irradiation on normal TGA thermograms for polymer blends containing the TA increased also the thermal stability comparing with the thermal stability of unirradiated and not containing the TA. The TA can act as energy sinks during irradiation process, this protects the polymer chain backbone from irradiation as well as TA can be scavenging the radicals and stabilized these radicals through the resonance in benzene rings [22]. From Table 1 and Table 2 and Figures 2-5 it can be seen that the main decomposition process for PVA, CMC and PVA/CMC blend occur in one step as in case of unirradiated PVA and PVA/CMC blends. The values of $\mathrm{T}_{\max }$ for unirradiated PVA and irradiated with $20 \mathrm{kGy}$ and $40 \mathrm{kGy}$ were found to be $345^{\circ} \mathrm{C}, 385^{\circ} \mathrm{C}$ and $345^{\circ} \mathrm{C}$ this $\mathrm{T}_{\max }$ was highly increased with adding the $\mathrm{TA}\left(402^{\circ} \mathrm{C}\right)$ the $\mathrm{T}_{\max }$ decreased with irradiation but still better than the unirradiated PVA.

\subsection{Differential Scanning Calorimetry (DSC)}

DSC analysis has proved to be valuable method for investigating the thermal parameters of polymeric systems. DSC curves were plotted for PVA/CMC blends and the blends containing constant ratio of $5 \%$ of TA compound, before and after gamma irradiation to different doses as shown in Figures 6-9. It should be noted that the $T_{g}$ was taken as the temperature of the first endothermic peak which is the enthalpy relaxation of the amorphous part, 
Table 1. Weight loss $(\%)$ and the temperatures of the maximum value of the rate of reaction $\left(\mathrm{T}_{\max }\right)$ at different heating temperatures of PVA/CMC blends, before and after they had been gamma irradiated to different doses.

\begin{tabular}{|c|c|c|c|c|c|c|c|c|}
\hline \multirow{2}{*}{$\begin{array}{c}\mathrm{PVA} / \mathrm{CMC} \\
\text { ratio }(\%)\end{array}$} & \multirow{2}{*}{$\begin{array}{l}\text { Dose } \\
\text { (kGy) }\end{array}$} & \multicolumn{5}{|c|}{ Weight loss (\%) } & \multirow[b]{2}{*}{$600^{\circ} \mathrm{C}$} & \multirow{2}{*}{$\begin{array}{l}\mathrm{T}_{\max } \\
\left({ }^{\circ} \mathrm{C}\right)\end{array}$} \\
\hline & & $100^{\circ} \mathrm{C}$ & $200^{\circ} \mathrm{C}$ & $300^{\circ} \mathrm{C}$ & $400^{\circ} \mathrm{C}$ & $500^{\circ} \mathrm{C}$ & & \\
\hline \multirow{3}{*}{$100 / 0$} & 0 & 3 & 5 & 15 & 80 & 90 & 93 & 345.0 \\
\hline & 20 & 4 & 9 & 17 & 68 & 93 & 100 & 385.0 \\
\hline & 40 & 4 & 8 & 17 & 79 & 87 & 92 & 345.0 \\
\hline \multirow{3}{*}{$80 / 20$} & 0 & 4 & 4.5 & 17 & 70 & 78 & 82 & 365.0 \\
\hline & 20 & 8 & 12 & 33 & 74 & 85 & 87 & 365.0 \\
\hline & 40 & 4 & 8 & 24 & 70 & 85 & 87 & 365.0 \\
\hline \multirow{3}{*}{$50 / 50$} & 0 & 4 & 8 & 17 & 61 & 70 & 73 & 345.0 \\
\hline & 20 & 6 & 11 & 30 & 72 & 80 & 84 & 365.0 \\
\hline & 40 & 10 & 13 & 25 & 66 & 76 & 79 & 345.0 \\
\hline \multirow{3}{*}{$0 / 100$} & 0 & 5 & 10 & 20 & 60 & 65 & 68 & 325.0 \\
\hline & 20 & 8 & 15 & 35 & 73 & 78 & 100 & 345.0 \\
\hline & 40 & 6 & 12 & 30 & 65 & 69 & 73 & 325.0 \\
\hline
\end{tabular}

Table 2. Weight loss (\%) and $\mathrm{T}_{\max }$ at different heating temperatures of PVA with different ratios of CMC and a constant ratio of TA $(5 \%)$, before and after they had been gamma irradiated to different doses.

\begin{tabular}{|c|c|c|c|c|c|c|c|c|}
\hline \multirow{2}{*}{$\begin{array}{c}\mathrm{PVA} / \mathrm{CMC} \\
\text { ratio (\%) }\end{array}$} & \multirow{2}{*}{$\begin{array}{l}\text { Dose } \\
\text { (kGy) }\end{array}$} & \multicolumn{5}{|c|}{ Weight loss (\%) } & \multirow[b]{2}{*}{$600^{\circ} \mathrm{C}$} & \multirow{2}{*}{$\begin{array}{l}\mathrm{T}_{\max } \\
\left({ }^{\circ} \mathrm{C}\right)\end{array}$} \\
\hline & & $100^{\circ} \mathrm{C}$ & $200^{\circ} \mathrm{C}$ & $300^{\circ} \mathrm{C}$ & $400^{\circ} \mathrm{C}$ & $500^{\circ} \mathrm{C}$ & & \\
\hline \multirow{3}{*}{$100 / 0$} & 0 & 1 & 3 & 6 & 55 & 80 & 87 & 402 \\
\hline & 20 & 3 & 5 & 13 & 60 & 90 & 100 & 385.0 \\
\hline & 40 & 3 & 5 & 15 & 77 & 88 & 90 & 365.0 \\
\hline \multirow{3}{*}{$80 / 20$} & 0 & 2 & 7 & 18 & 73 & 83 & 85 & 370 \\
\hline & 20 & 2 & 5 & 24 & 70 & 83 & 87 & 365.0 \\
\hline & 40 & 6 & 8 & 25 & 72 & 83 & 87 & 365.0 \\
\hline \multirow{3}{*}{$50 / 50$} & 0 & 3 & 8 & 13 & 67 & 75 & 78 & 350 \\
\hline & 20 & 6 & 9 & 25 & 66 & 79 & 88 & 345.0 \\
\hline & 40 & 8 & 11 & 23 & 72 & 74 & 79 & 345.0 \\
\hline \multirow{3}{*}{$0 / 100$} & 0 & 5 & 10 & 21 & 65 & 69 & 70 & 331 \\
\hline & 20 & 3 & 11 & 29 & 68 & 73 & 76 & 325.0 \\
\hline & 40 & 4 & 11 & 27 & 65 & 70 & 72 & 325.0 \\
\hline
\end{tabular}

the $\mathrm{T}_{\mathrm{m}}$ was taken as the second endothermic peak which is due to the melting of the crystalline part of the blend. The first transition starts at $50^{\circ} \mathrm{C}$ for PVA and ends with endothermic transition around $140^{\circ} \mathrm{C}$, the maximum of this peak was at $105^{\circ} \mathrm{C}$ as shown in Figure 6. The reported glass transition temperatures in the literature for 

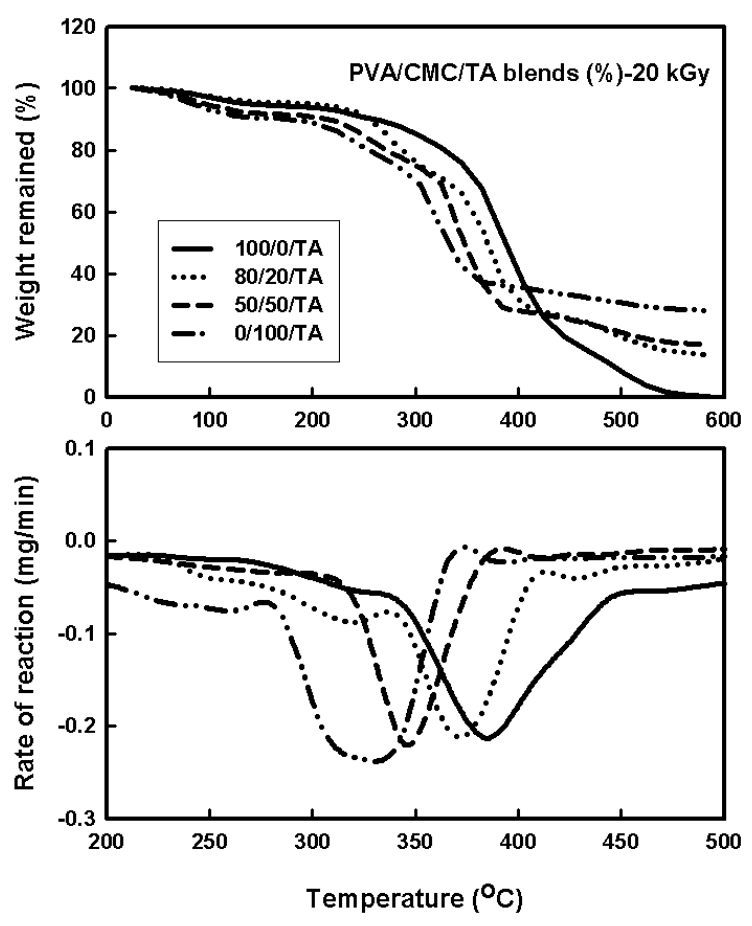

Figure 4. TGA thermograms and the rate of thermal decomposition reaction of different compositions of PVA/CMC blends and containing a constant ratio (5\%) of TA compound, gamma irradiated to a dose of $20 \mathrm{kGy}$.
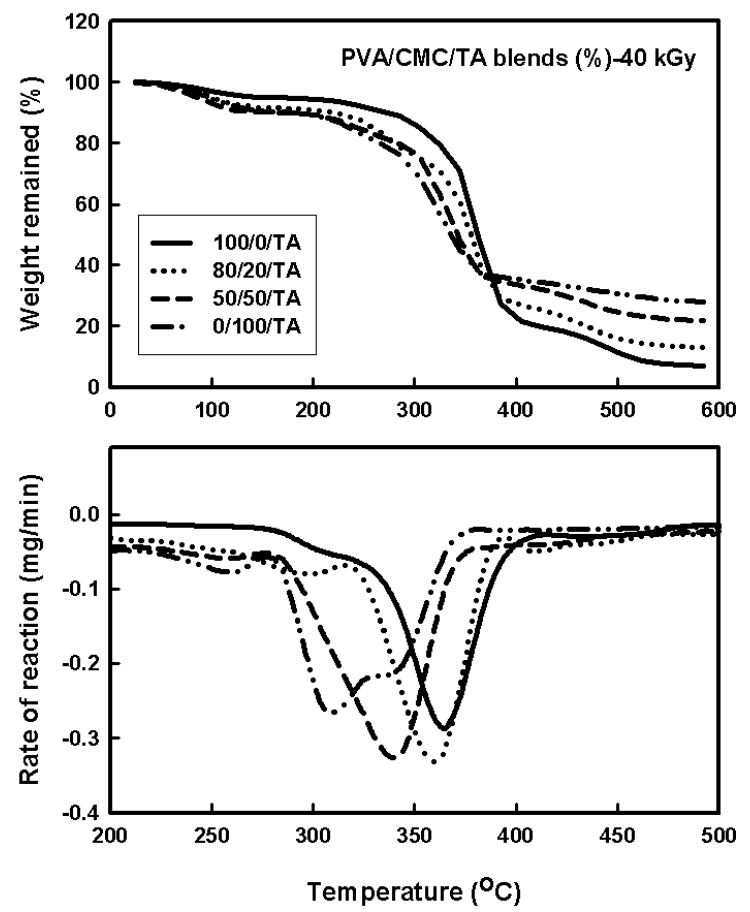

Figure 5. TGA thermograms and the rate of thermal decomposition reaction of different compositions of PVA/CMC blends and containing a constant ratio (5\%) of TA compound, gamma irradiated to a dose of $40 \mathrm{kGy}$. 
PVA and CMC were 84 and $150^{\circ} \mathrm{C}$, respectively, depending on the plasticizer used and the thermal history of the samples. As shown in Figure 7, the addition of TA to the PVA, CMC and their blends, the TA compound acts as a plasticizers and decreases the endothermic peaks without changes on the shape of thermal transition in the polymers.

The DSC thermograms for gamma irradiated PVA, CMC and PVA/CMC (50/50\%) blends with TA showed two endothermic peaks due to the glass transition temperature $\left(T_{g}\right)$ and the melting temperature $\left(T_{m}\right)$ as shown in Figure 8 and Figure 9. It can be seen that the value of Tg decreased with increasing irradiation dose for CMC and PVA and another decrease in the $\mathrm{T}_{\mathrm{m}}$ due to the gamma irradiation of the blends. On the other hand, the thermograms of the irradiated blend suggest a semi-crystalline nature of the blend.

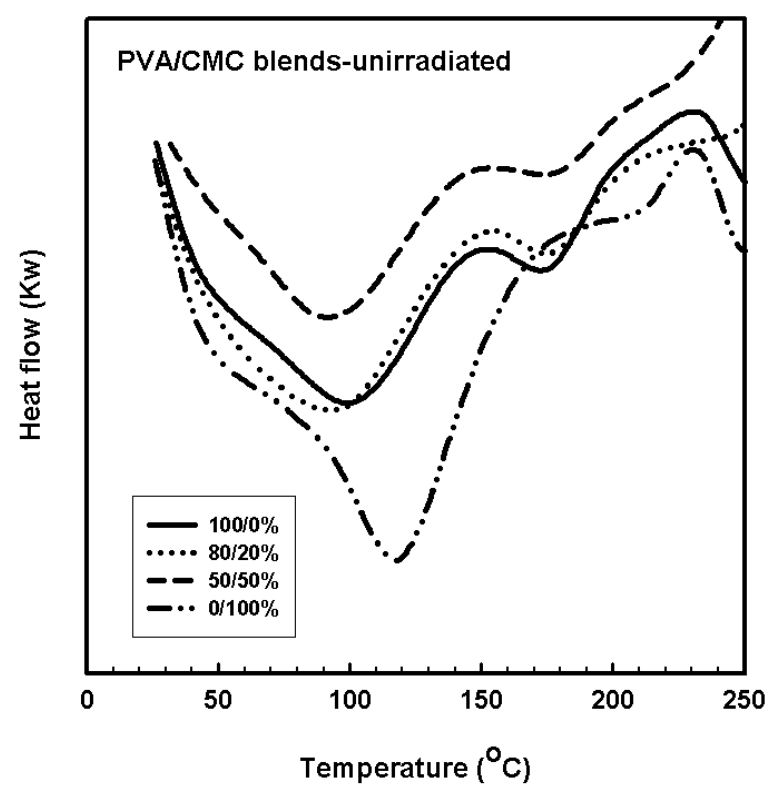

Figure 6. DSC thermograms of unirradiated PVA/CMC blend of different compositions.

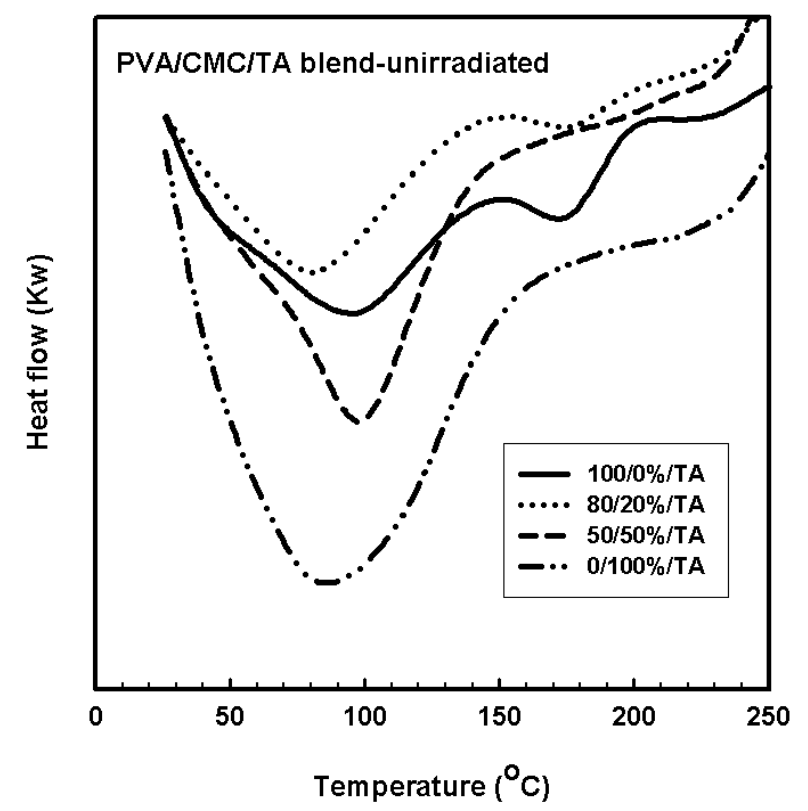

Figure 7. DSC thermogram of unirradiated PVA/CMC blends and contains a constant ratio (5\%) of the TA compound. 


\subsection{Dynamic Mechanical Analysis (DMA)}

Many polymers show specific characteristic modulus changes and absorption peaks at specific temperatures, which can be used as a "fingerprint" of a particular polymer, leading to identification of important properties such as atoms or molecular relaxation. One of the goals of this measurement is to understand the effect of blending and irradiation on the mobility of PVA polymer at molecular level. DMA spectra of PVA, CMC and their blends, before and after gamma irradiation to different doses are shown in Figures 10-12. In these curves, the temperature dependency of the loss modulus, E" (energy cannot stored and cannot be recovered), storage modulus, $\mathbf{E}^{\prime}$ (the energy can be stored and can be recovered), and the (tan delta) was plotted. The E' value for $\mathrm{CMC}$ polymer was higher than that for PVA. At above $100^{\circ} \mathrm{C}$, the decrease of $\mathbf{E}^{\prime}$ was suppressed for the PVA/CMC blends compared with that of PVA. This is because when materials turn to be soft, the H-bonding

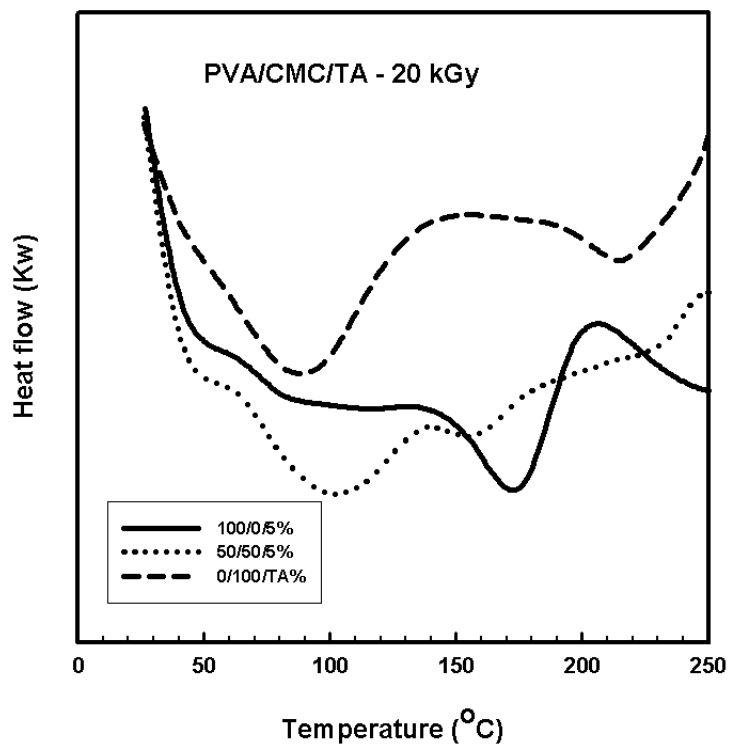

Figure 8. DSC thermograms of PVA/CMC blend and contain a constant ratio $(5 \%)$ of the TA compound, gamma irradiated to a dose of $20 \mathrm{kGy}$.

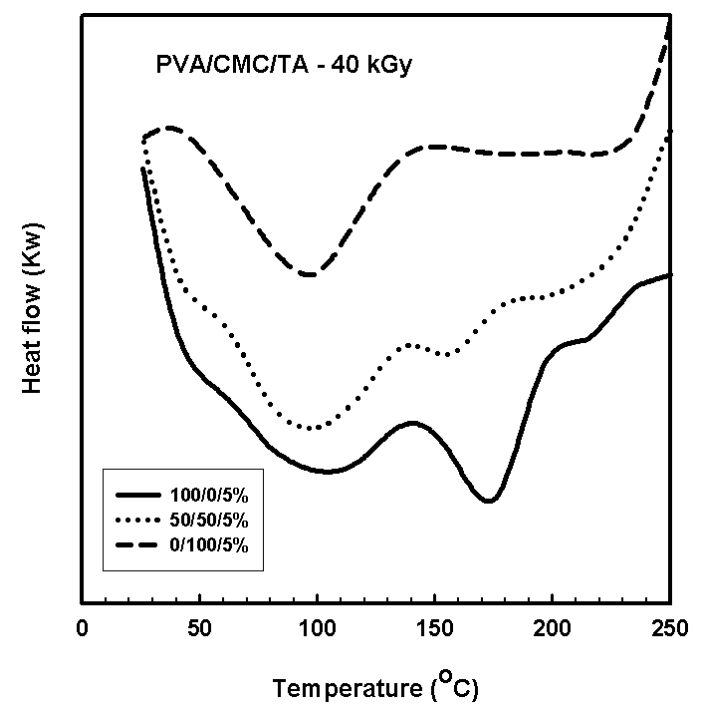

Figure 9. DSC thermograms of PVA/CMC blend and contain a constant ratio (5\%) of the TA compound, gamma irradiated to a dose of $40 \mathrm{kGy}$. 
effect and side chain of the CMC determines the characteristics of the blend due to the restricted movement of the polymer chains. It can be seen that with increasing the temperature the chain mobility increased either in side chains or in the groups of adjacent backbone atoms resulting in lower modulus.

As the free volume continues to increase with increasing temperature, we reach the glass transition, $T g$, where large segments of the chain start moving. This transition is also called the alpha transition, $T \mathrm{a}$. The $T \mathrm{~g}$ is very dependent on the degree of polymerization up to a value known as the critical $\mathrm{Tg}$ or the critical molecular weight. Above this value, the $T \mathrm{~g}$ typically becomes less dependent on molecular weight. This movement occurred in PVA at temperature less than the expected because of the presence of glycerol. The presence of PVA in the PVA/CMC (50/50) blends decreases the alpha transition due to decrease the side chain movement through hydrogen bonding.

From Figure 11 and Figure 12, it can be seen that loss modulus and storage modulus values were less than unirradiated PVA and CMC polymers. This decrease due to gamma irradiation of polymers has two probabilities; the first probability was the crosslinking due to radical formation on the adjacent radical chains and the second probability was the degradation that occurs in the polymer chains. The radiation effect on the polymer is combination between these two effects, if the degradation is majored reactions, the overall properties will be degradation otherwise, and the crosslinking is the prominent. The effect of radiation on the CMC modulus properties improved the working temperature in comparison with the unirradiated CMC. These properties were improved in PVA/CMC blends. On the other hand, increasing irradiation doses from $20 \mathrm{kGy}$ to $40 \mathrm{kGy}$ decreases the modulus properties this decrease is due to increasing the degradation on the chains.

Figure 13 and Figure 14 show the temperature dependency of the storage modulus $\left(E^{\prime}\right)$, loss modulus (E") and (tan delta) of the PVA, CMC and their blends that containing TA. When TA is added to the PVA, CMC and the blends it increases the modulus properties of the PVA whereas it decreases in case of CMC this increase in PVA modulus occurs at room temperature, by increasing the temperature the modulus decreased faster compared with the pure PVA. This faster decrease may be due to that PVA can form $\mathrm{H}$ bonding easier than CMC, TA has hindered structure that can not easily form hydrogen bonding whereas PVA has linear chains can favorably for hydrogen bonding. With increasing, the temperature the hydrogen bonding between PVA and TA de-

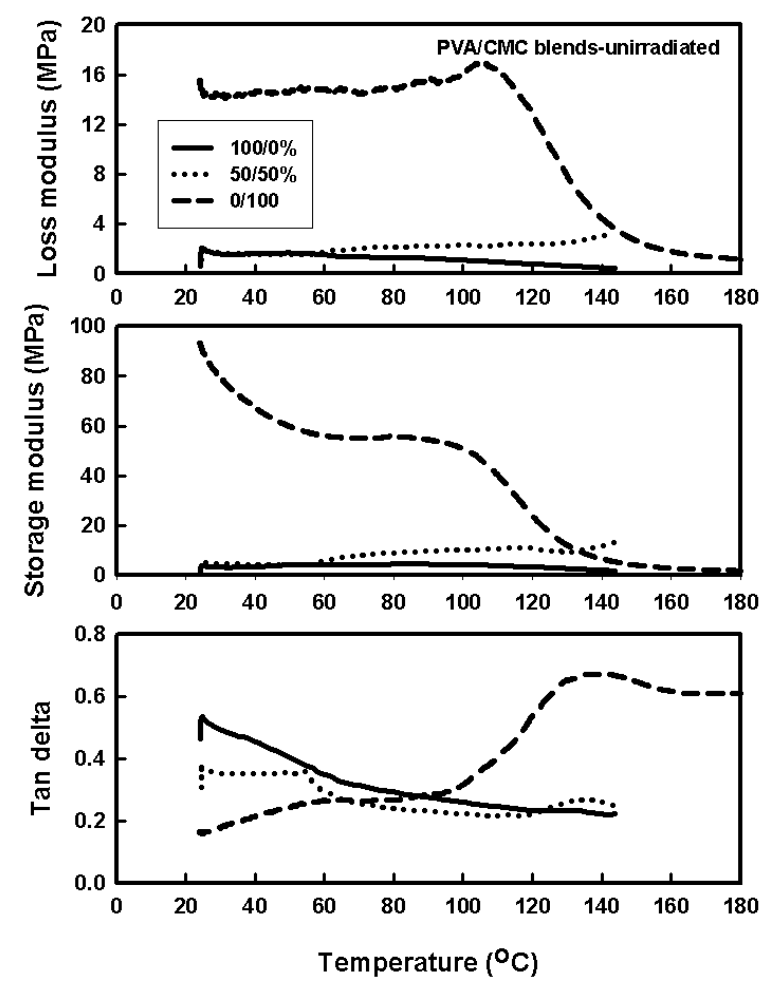

Figure 10. Temperature dependency plots of the dynamic mechanical properties of unirradiated PVA/CMC blends. 

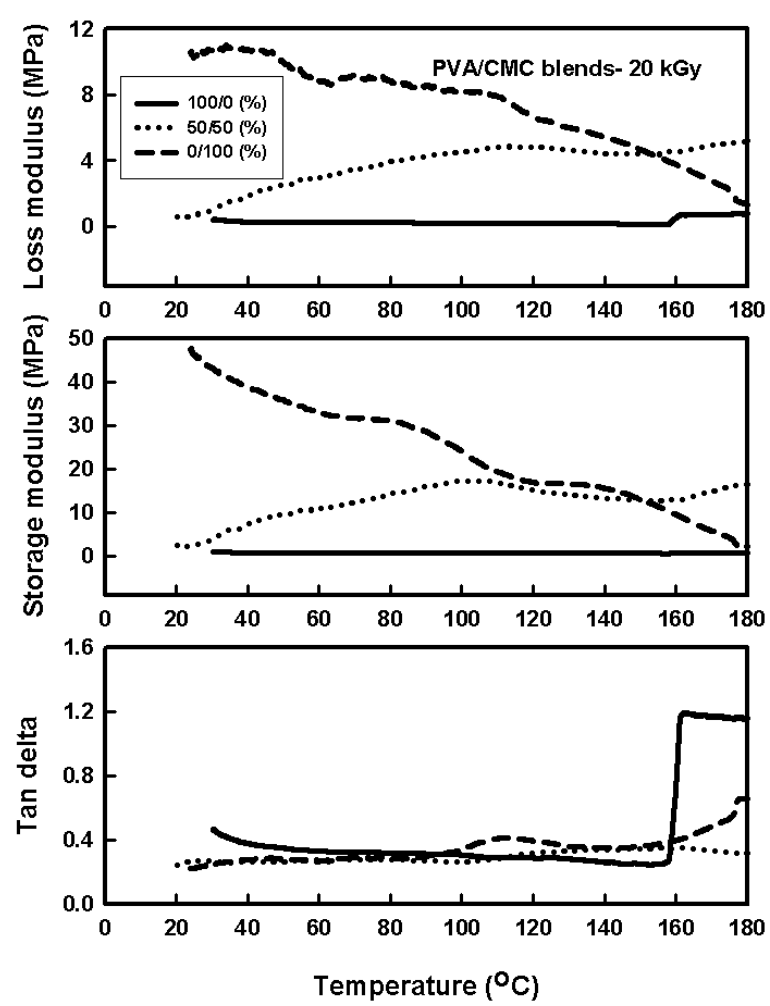

Figure 11. Temperature dependency plots of the dynamic mechanical properties of PVA/CMC blends, gamma irradiated to a dose of $20 \mathrm{kGy}$.
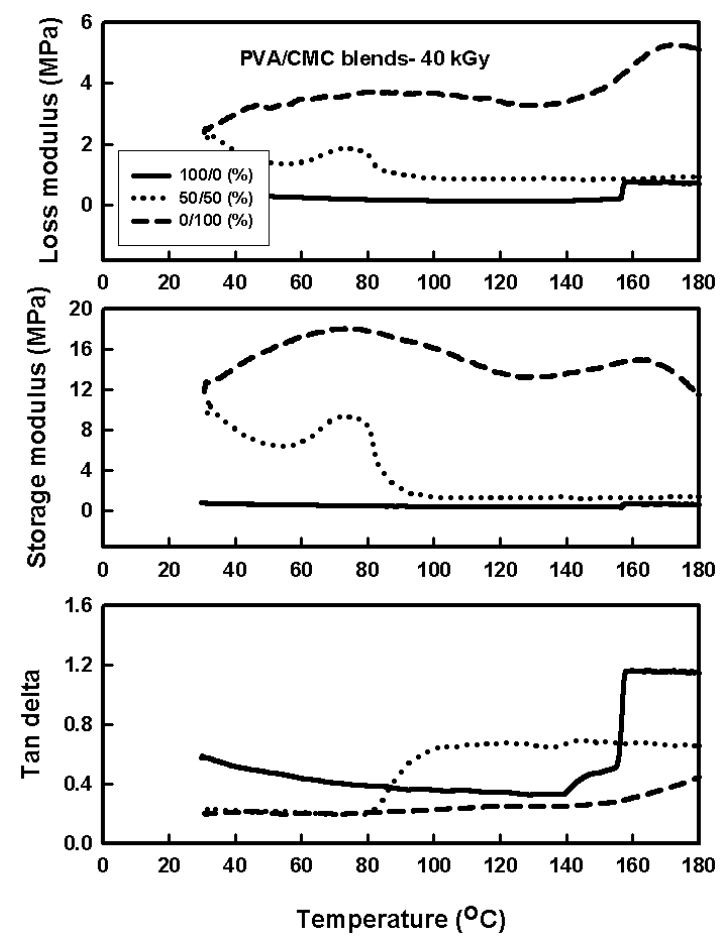

Figure 12. Temperature dependency plots of the dynamic mechanical properties of PVA/CMC blends, gamma irradiated to a dose of $40 \mathrm{kGy}$. 
composed and the TA working as plasticizer increasing the chain movement and decreasing the modulus. On the other hand, this effect is less in PVA/CMC and CMC polymer. Also from figures, it can be seen that the peaks in tan delta for PVA/CMC blends and CMC were decreased and this may be due to that the TA molecules and glycerol increases the side chain movement.

The effect of phenolic compounds on the mechanical properties of irradiated PVA, CMC and PVA/ $\mathrm{CMC}(50 / 50)$ was improved in comparison with that for irradiated PVA, CMC and PVA/CMC (50/50) without phenolic compound. This improvement may be due to that phenolic compound can act as antioxidant and antirads through providing liable hydrogen that terminate radiation induced radicals on the polymer chains [22].

\subsection{Application of PLST/PVA Blends as Edible Materials}

Fruits and vegetables continue to respire and transpire after harvesting as living organisms. They are characterized by a high respiration rate and reducing the respiration and transpiration rates can extend their shelf life. This reducing can be done by controlling some factors such as temperature, relative humidity, light and mechanical damage, using some treatments as waxing and irradiation [23]-[25]. They reported that the edible films and coatings are thin layers that act as a barrier to the external factors such as (oxygen, oil and water vapor) and thus protect the food products and extend their shelf life.

$\mathrm{PVA} / \mathrm{CMC} / \mathrm{TA}$ blends in this section are considered biodegradable polymers, edible materials and were used as coating for fruits like banana. TA was used as antibacterial material. Five groups of banana were surface coated by these blends. The first one was untreated group and served as a control as shown in Figure 15. The second group was surface coated with unirradiated PVA polymer solution as shown in Figure 16, whereas the third group was surface coated with unirradiated CMC polymer solution as shown in Figure 17. The forth group was surface coated with unirradiated PVA/CMC/TA blend (50/50\%) solution as shown in Figure 18 whereas the fifth group was surface coated with gamma irradiated PVA/CMC/TA blend (50/50\%) solution as shown in Figure 19. It can be seen that banana with irradiated solution has prolonged the storage life from 9 to 19 days. At the $19^{\text {th }}$ day, banana kept good color natural and ripening, whereas the control is damaged completely and the fruits, which was coated with unirradiated blend, could not prevent the ripening. This effect is due to:

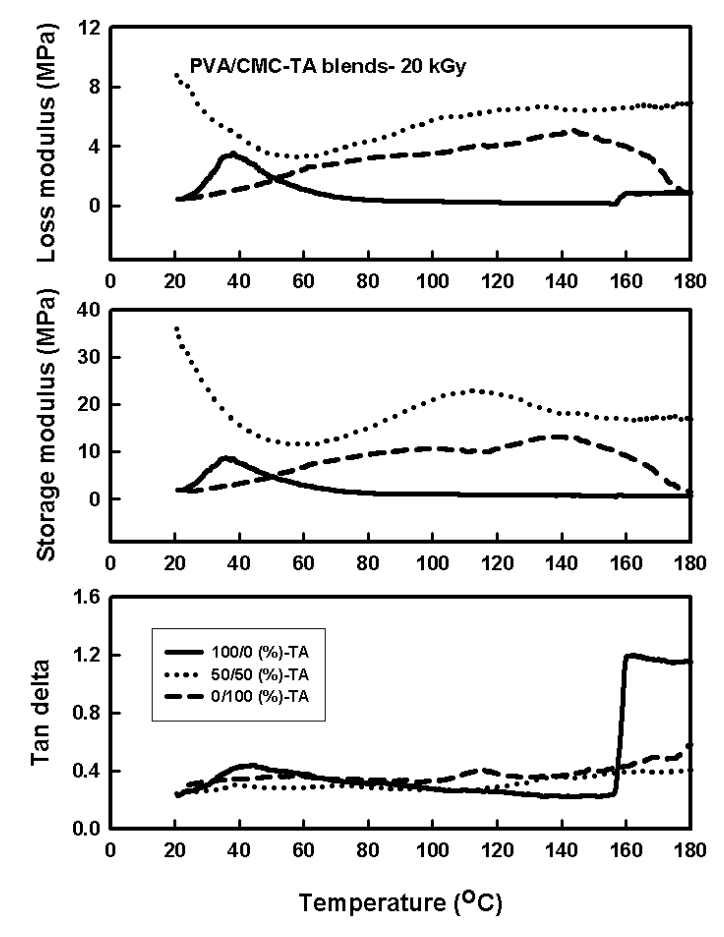

Figure 13. Temperature dependency plots of the dynamic mechanical properties of PVA/CMC blends and contain a constant ratio (5\%) of the TA compound, gamma irradiated to a dose of $20 \mathrm{kGy}$. 

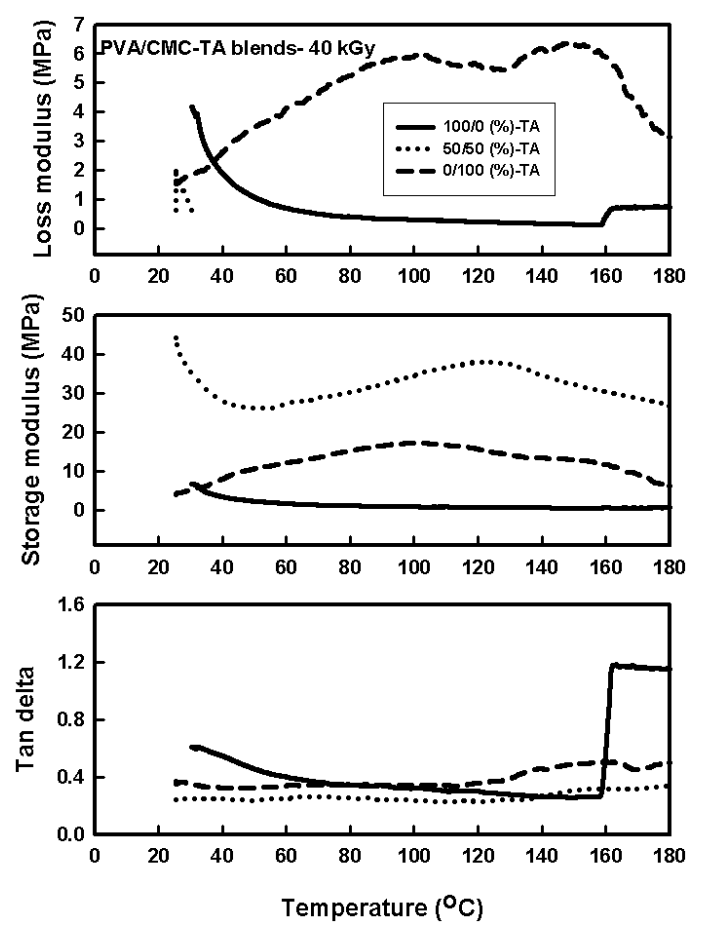

Figure 14. Temperature dependency plots of the dynamic mechanical properties of PVA/CMC blends and contain a constant ratio (5\%) of the TA compound, gamma irradiated to a dose of $40 \mathrm{kGy}$.

1) The antimicrobial effect of TA, which prevents the attack of microorganisms.

2) The homogeneous coating would prevent the transfer of humidity and oxygen to fruits, which prevent any deterioration in the fruits.

3) The gamma irradiated films with improved mechanical and thermal properties will eventually withstand and protect the fruits against stresses and temperature.

4) The anti-fungal activity and the change in physico-chemical properties of blend by gamma irradiation.

From above data we can concluded that, biodegradable polymer blends based on various different ratios of poly(vinyl alcohol) (PVA) and carboxymethyl cellulose (CMC) were prepared by casting solution techniques. The thermal stability of unirradiated blends containing constant ratio of tannic acid indicated that tannic acid improve the thermal stability of PVA and this improvement decreases in case of CMC and in the blends. DSC thermograms were found that there is one $T_{g}$ for the blend before and after irradiation due to occurrence of some compatibility between PVA and CMC specially at ratio (80/20). Also, Dynamic mechanical properties of PVA, $\mathrm{CMC}$ and $\mathrm{PVA} / \mathrm{CMC}$ at different ratio before and after irradiation were studied and it was found that storage and loss modulus for CMC was higher than that for PVA, these properties decreased with irradiation. Application of irradiated PVA/CMC/tannic acid was investigated as coating materials for the fruit preservation. The coating of banana with gamma-irradiated blend has prolonged the storage life from 9 to 19 days. At the $19^{\text {th }}$ day, banana kept good natural colour and ripening, whereas the control is damaged completely and the fruit coated with the unirradiated blend could not prevent the ripening.

\section{Conclusion}

In this work, biodegradable polymer blends based on various ratio of poly(vinyl alcohol) and carboxymethyl cellulose were prepared by casting solution techniques. The thermal stability of PVA was improved by adding TA and irradiation whereas; this improvement was decreased in case of CMC and the blends. In addition, dynamic mechanical properties of PVA, CMC and PVA/CMC at different ratios before and after irradiation were studied and it was found that storage and loss modulus for CMC were higher than that for PVA, these properties decreased with irradiation. Application of irradiated PVA/ CMC/tannic acid blends as coating materials for the 


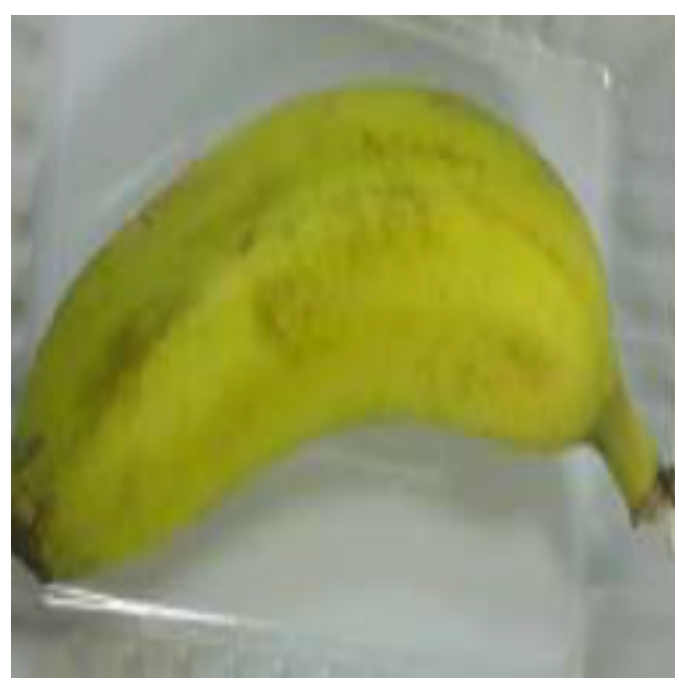

0 dye

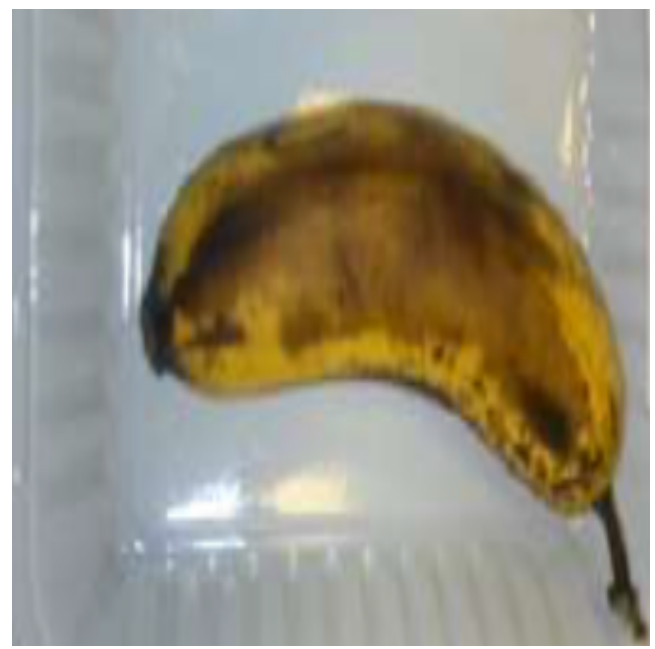

9 dyes

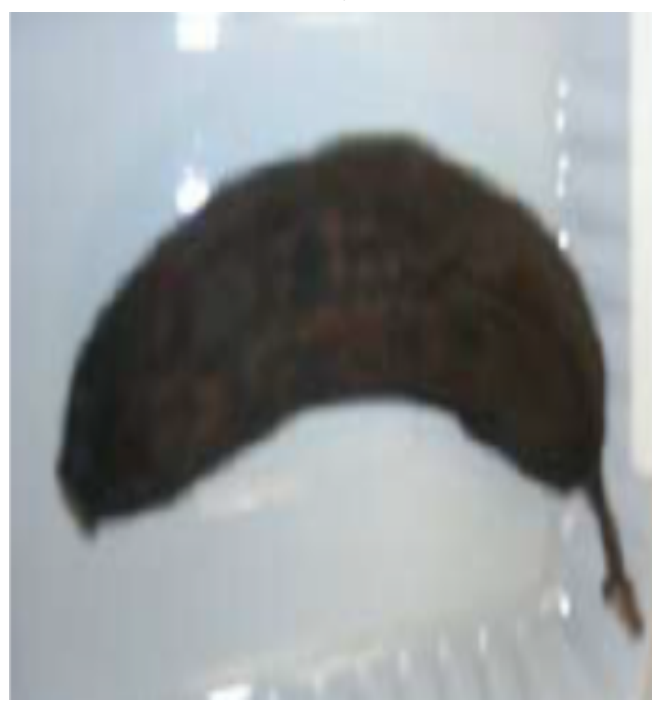

19 dyes

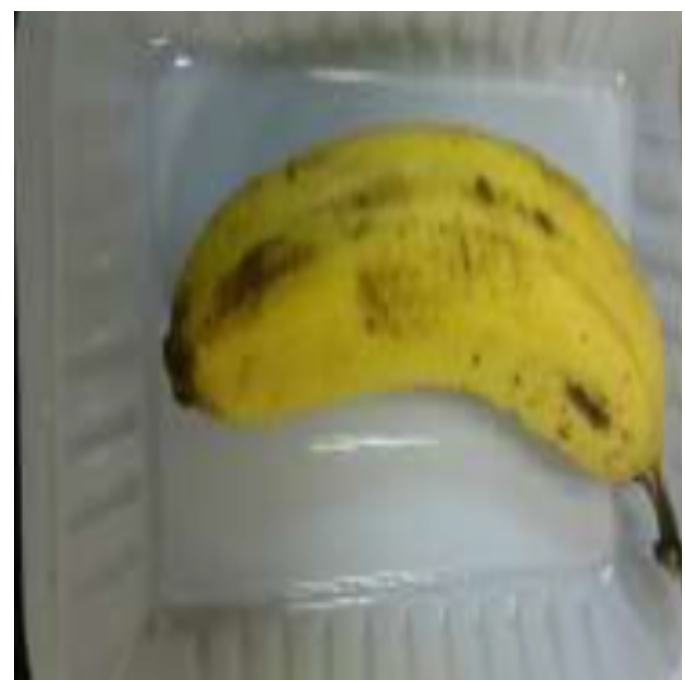

5 dyes

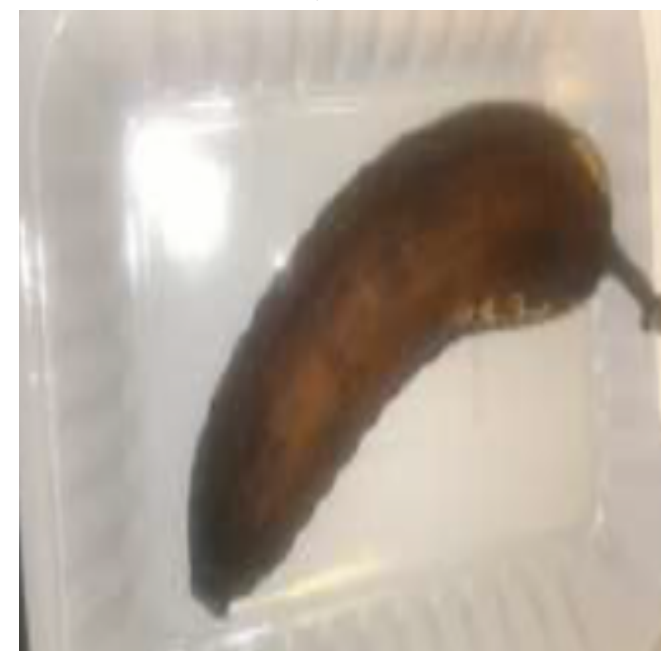

14 dyes

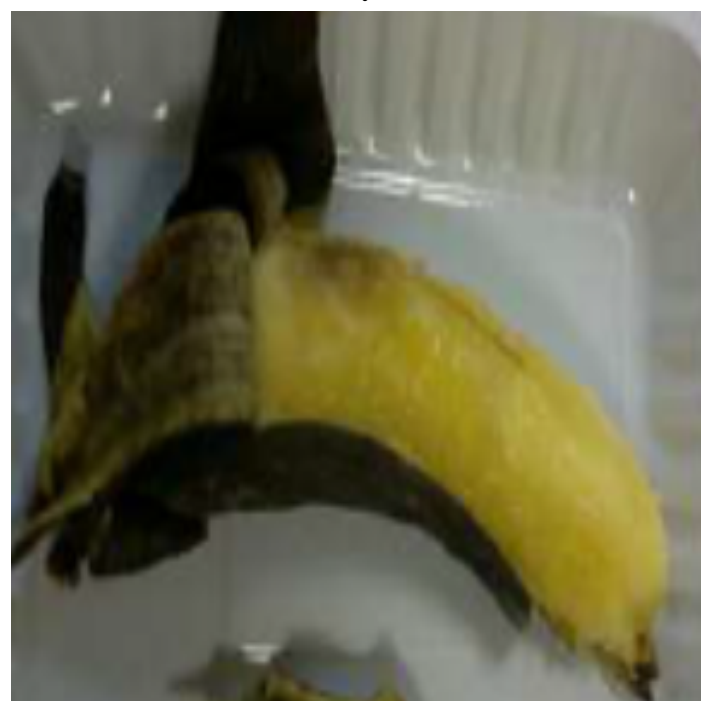

19 dyes (pealed)

Figure 15. Photomicrographs of untreated banana fruits taken after different days at room temperature. 


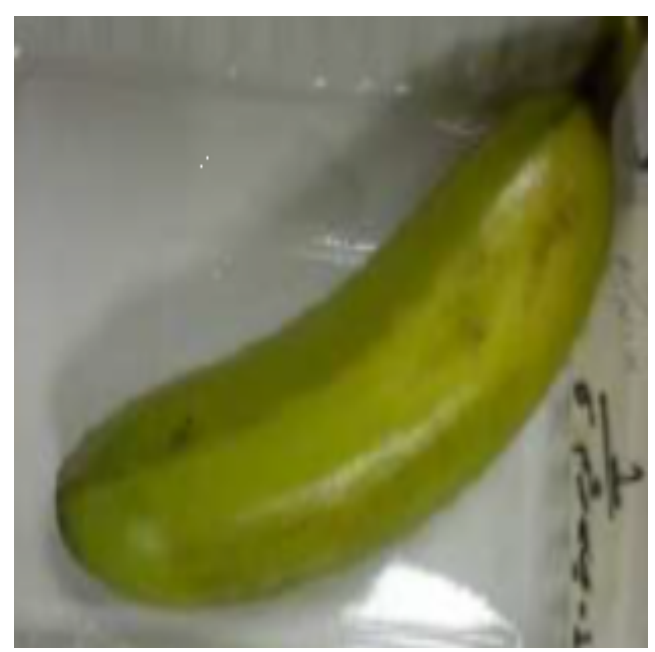

0 dyes

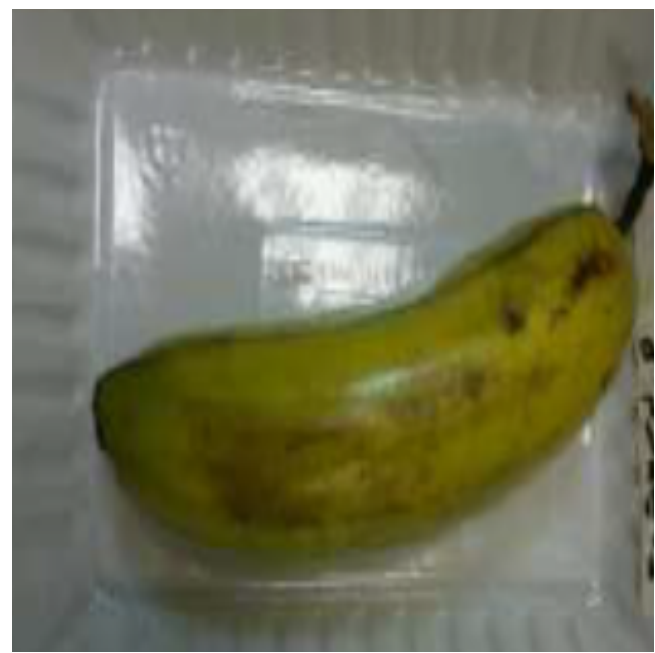

9 dyes

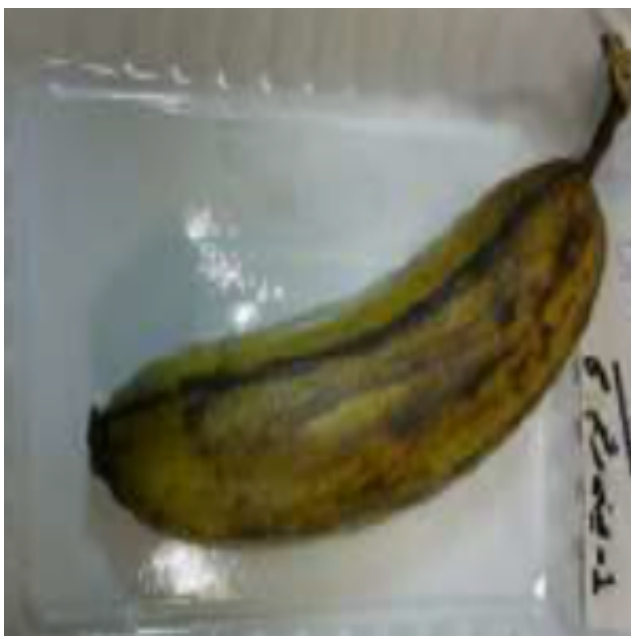

19 dyes

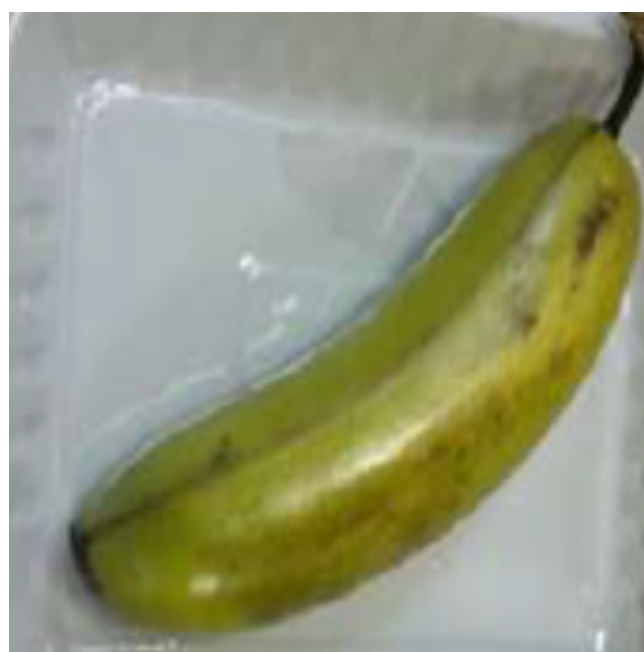

5 dyes

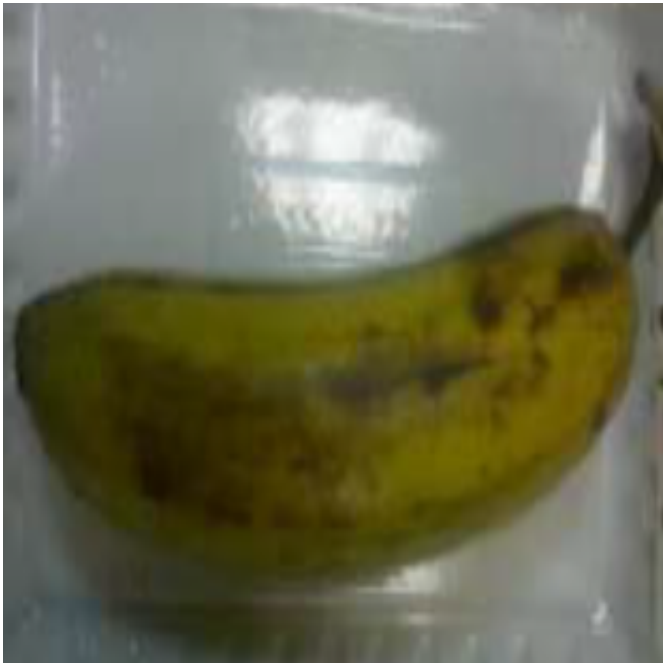

14 dyes

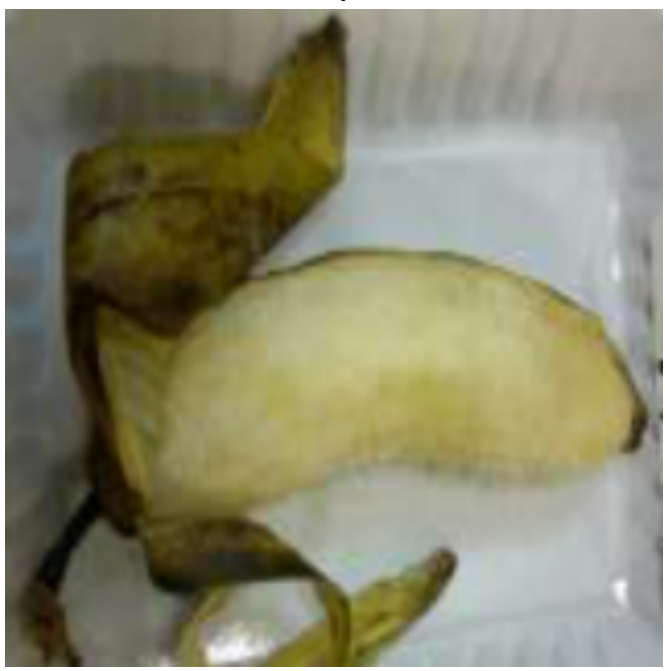

19 dyes (pealed)

Figure 16. Photomicrographs of banana fruits treated by surface coating with unirradiated PVA polymer solution taken after different days at room temperature. 


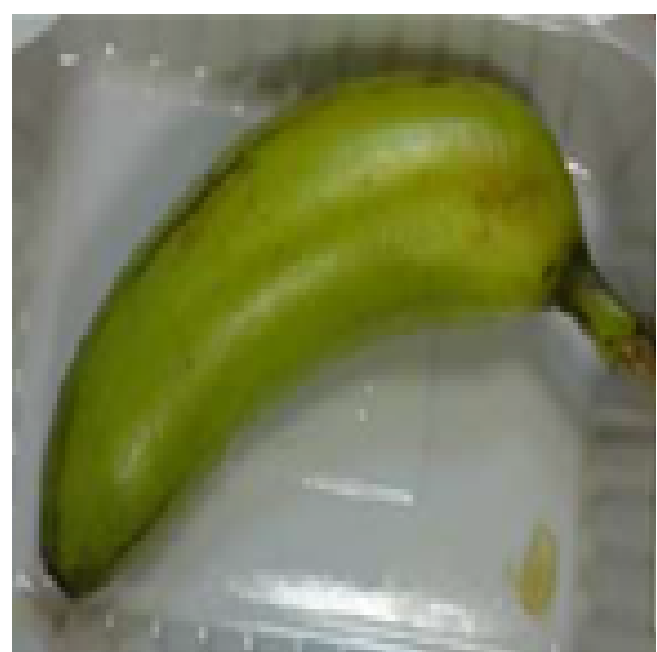

0 dyes

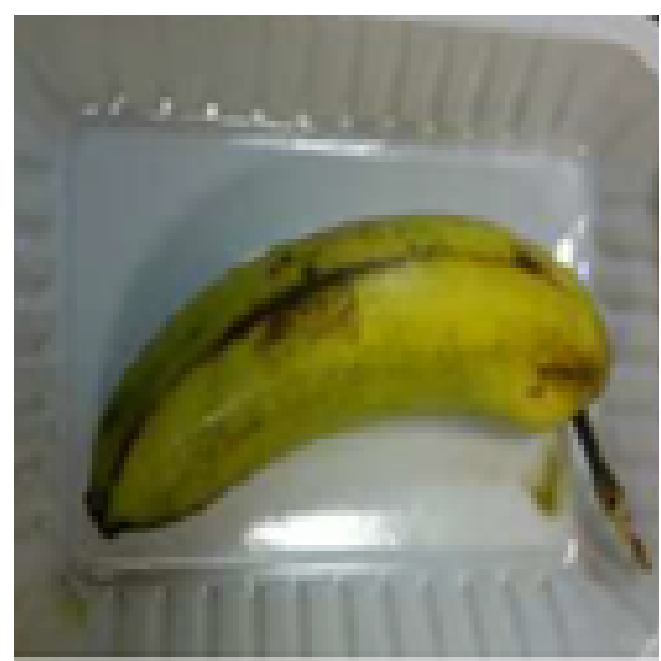

9 dyes

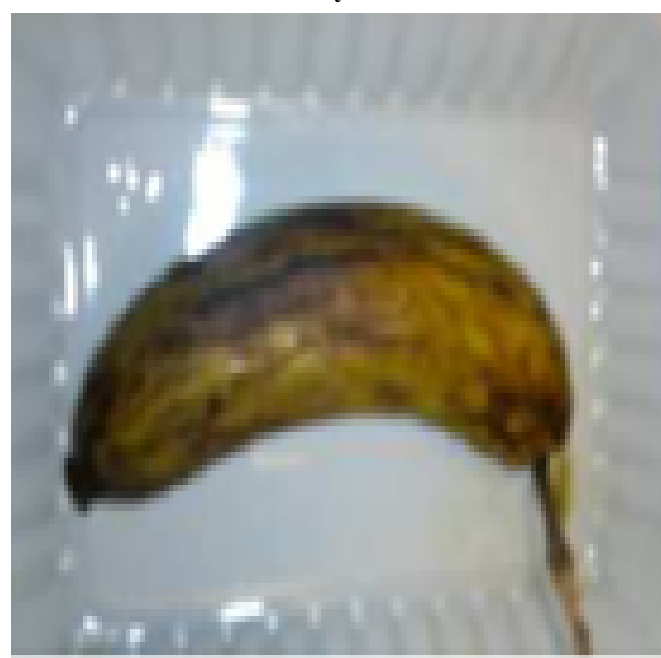

19 dyes

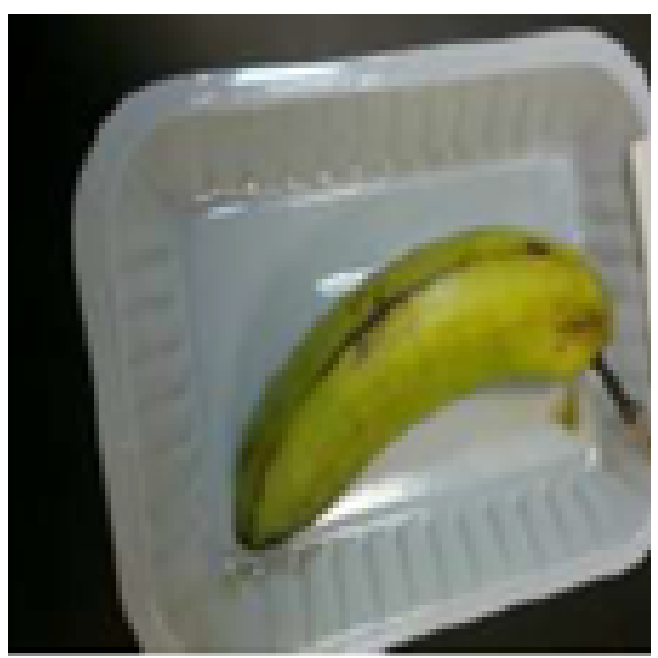

5 dyes

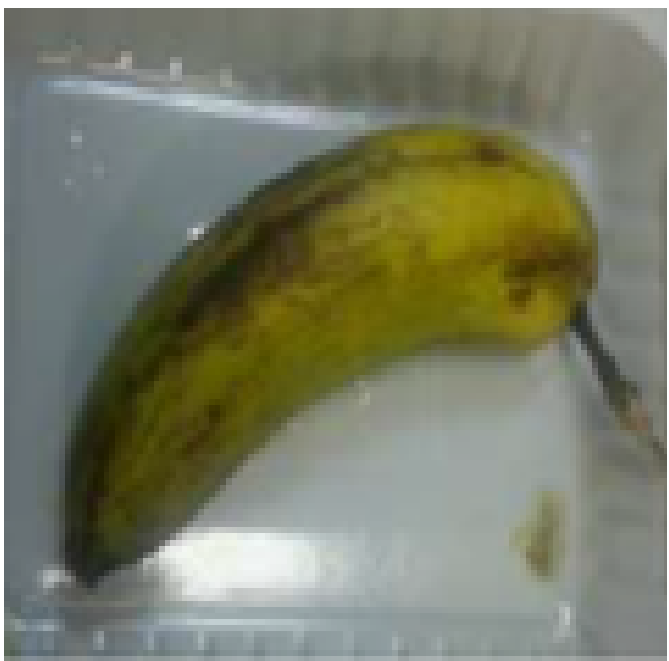

14 dyes

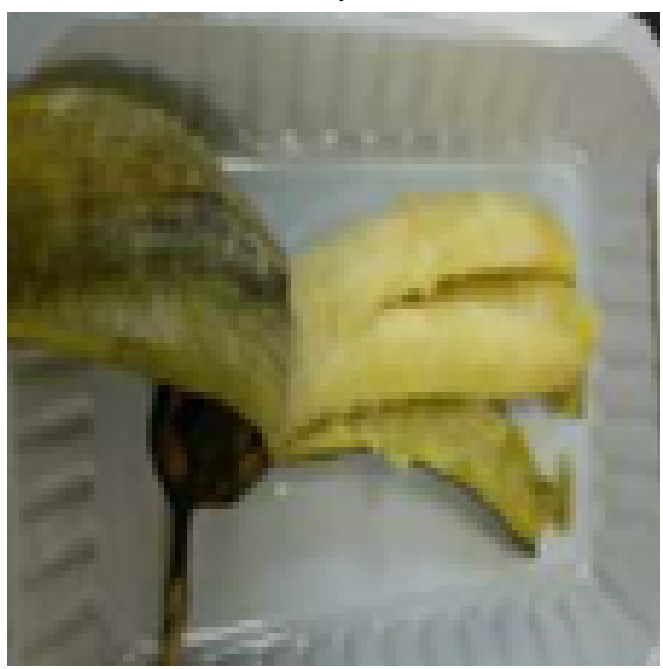

19 dyes (pealed)

Figure 17. Photomicrographs of banana fruits treated by surface coating with unirradiated CMC solution, pictures were taken after different days at room temperature. 


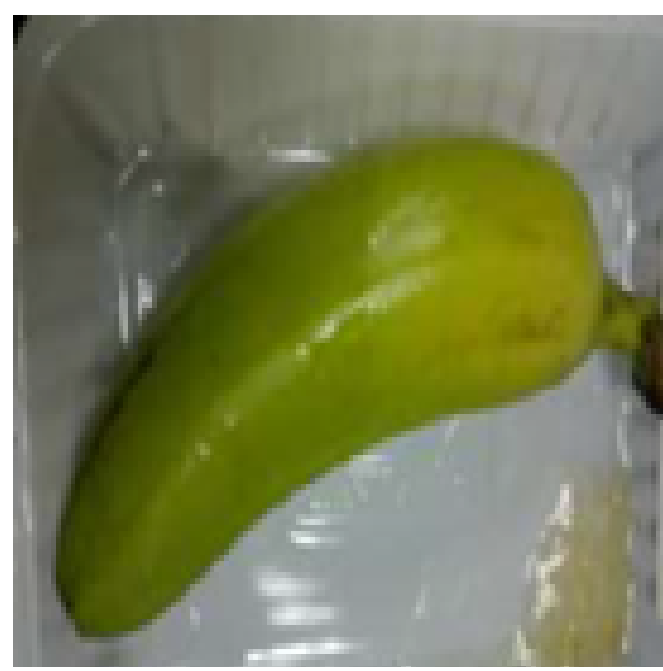

0 dyes

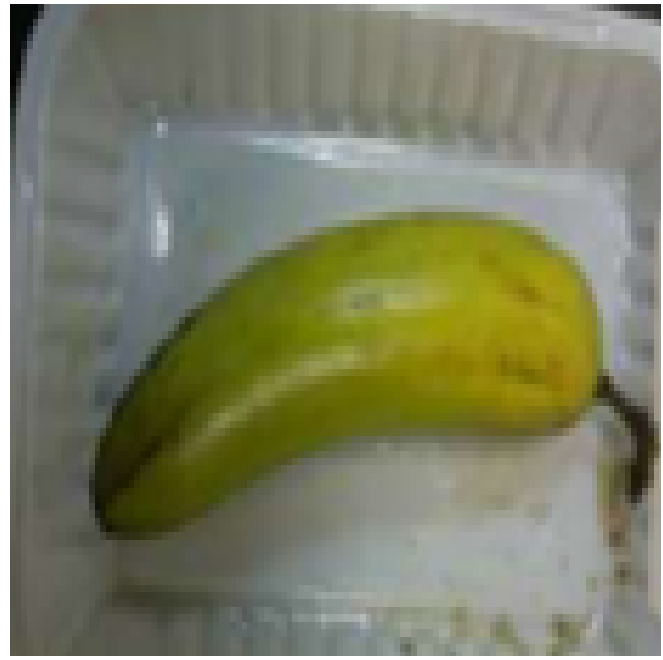

9 dyes

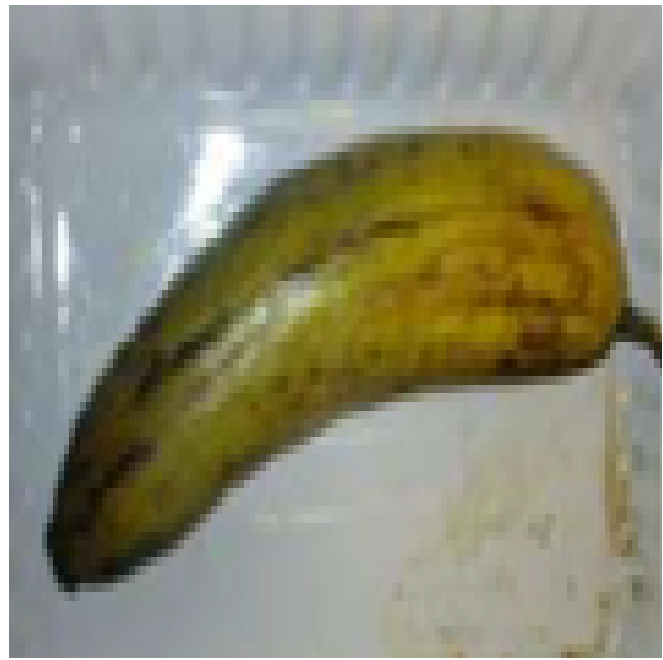

19 dyes

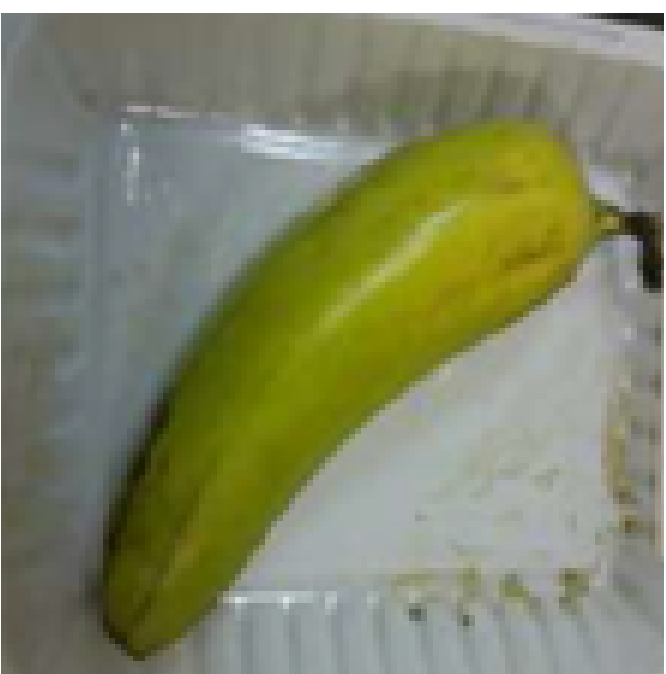

5 dyes

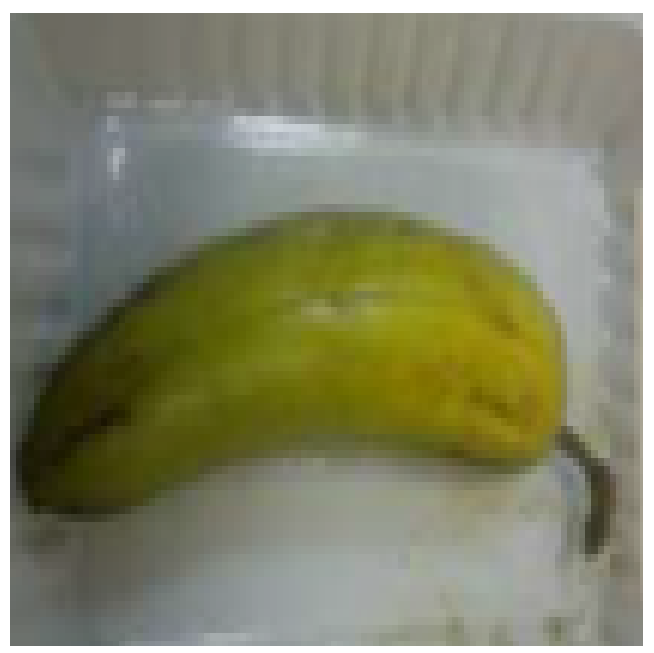

14 dyes

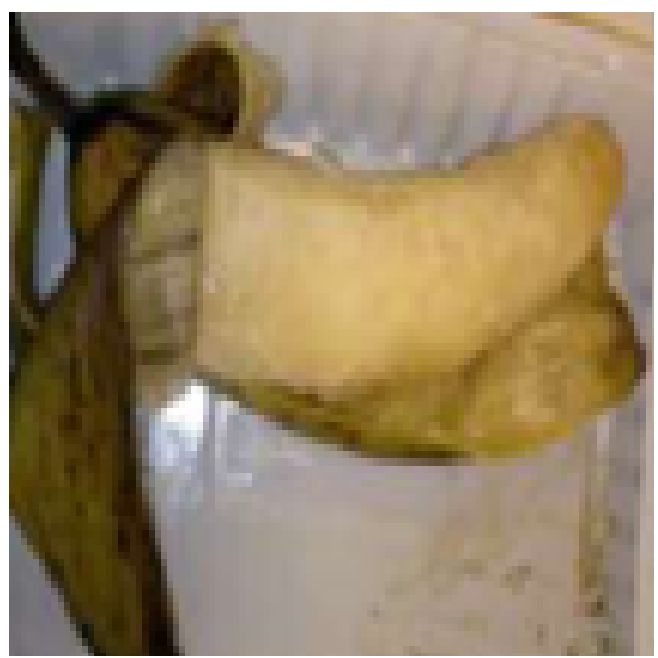

19 dyes (pealed)

Figure 18. Photomicrographs of banana fruits treated by surface coating with unirradiated PVA/CMC/TA blend $(50 / 50 \%)$, pictures were taken after different days at room temperature. 


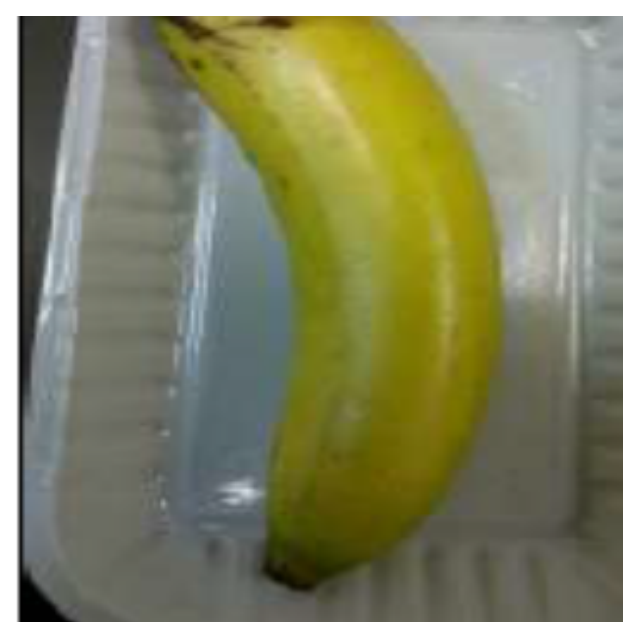

5 dyes

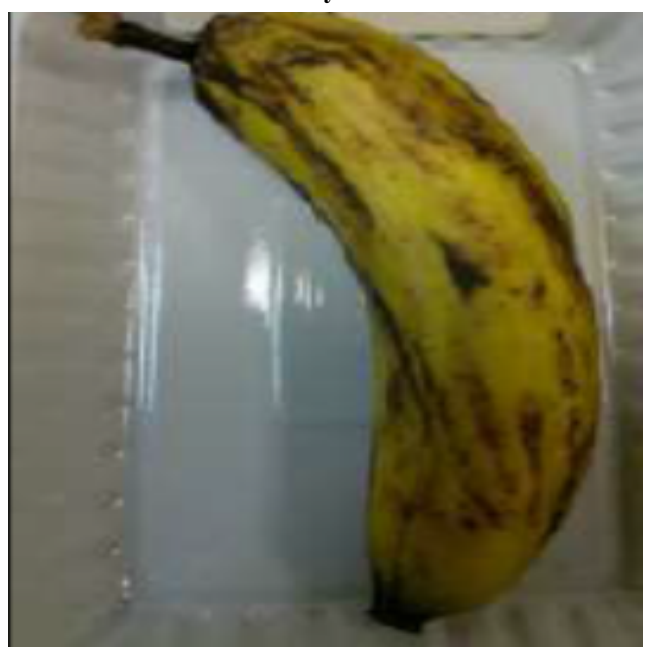

19 dyes

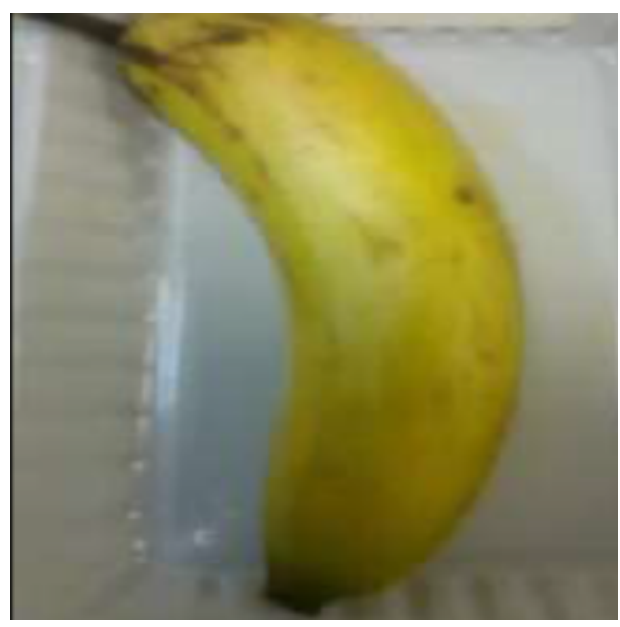

14 dyes

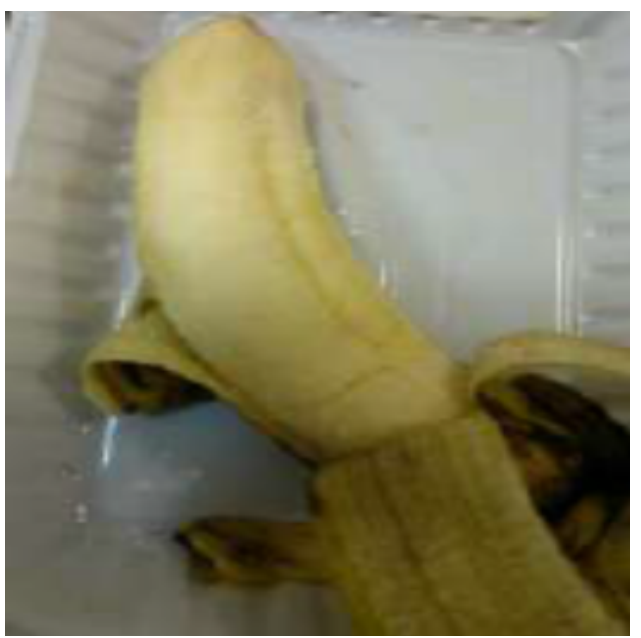

19 dyes (pealed)

Figure 19. Photomicrographs of banana fruits treated by surface coating with gamma irradiated $\mathrm{PVA} / \mathrm{CMC} / \mathrm{TA}$ blend $(50 / 50 \%)$, pictures were taken after different days at room temperature.

fruit preservation was investigated. The coating of banana with gamma-irradiated blend has prolonged the storage life from 9 to 19 days. At the $19^{\text {th }}$ day, banana kept good natural colour and ripening, whereas the control is damaged completely and the fruit coated with the unirradiated blend could not prevent the ripening.

\section{Acknowledgments}

The authors would like to thank King Abdulaziz City for Science and Technology/Petrochemicals Research Institute for supporting, enthusiasm and encouragement throughout this work.

\section{References}

[1] Velickova, E., Winkelhausen, E., Kuzmanova, S., Vitor, D.A. and Moldão-Martins, M. (2013) Impact of Chitosan-Beeswax Edible Coatings on the Quality of Fresh Strawberries (Fragaria Ananassa cv Camarosa) under Commercial Storage Conditions. LWT-Food Science and Technology, 52, 80-92.

[2] Bonilla, J., Atarés, L., Vargas, M. and Chiralt, A. (2012) Edible Films and Coatings to Prevent the Detrimental Effect of Oxygen on Food Quality: Possibilities and limitations. Journal of Food Engineering, 110, 208-213. http://dx.doi.org/10.1016/i.jfoodeng.2011.05.034

[3] Arnon, H., Zaitsev, Y., Porat, R. and Poverenov, E. (2014) Effects of Carboxymethyl Cellulose and Chitosan Bilayer Edible Coating on Postharvest Quality of Citrus Fruit. Postharvest Biology and Technology, 87, 21-26. 
http://dx.doi.org/10.1016/j.postharvbio.2013.08.007

[4] Azarakhsh, N., Osman, A., Ghazali, H.M., Tan, C.P. and Adzahan, N.M. (2014) Lemongrass Essential Oil Incorporated into Alginate-Based Edible Coating for Shelf-Life Extension and Quality Retention of Fresh-Cut Pineapple. Postharvest Biology and Technology, 88, 1-7. http://dx.doi.org/10.1016/j.postharvbio.2013.09.004

[5] Gol, N.B., Patel, P.R. and Ramana Rao, T.V. (2013) Improvement of Quality and Shelf Life of Strawberries with Edible Coatings Enriched with Chitosan. Postharvest Biology and Technology, 85, 185-195.

http://dx.doi.org/10.1016/j.postharvbio.2013.06.008

[6] Miguel, A.C., Lima, A.M., Teixeira, J.A., Moreira, R.A. and Vicente A. A. (2009) Suitability of Novel Galactomannans as Edible Coatings for Tropical Fruits. Journal of Food Engineering, 94, 372-378. http://dx.doi.org/10.1016/j.jfoodeng.2009.04.003

[7] Rojas-Grau, M.A., Raybaudi-Massilia, R.M., Soliva-Fortuny, R.C., Avena-Bustillos, R.J., McHughb, T.H. and MartnBelloso, O. (2007) Apple Puree-Alginate Edible Coating as Carrier of Antimicrobial Agents to Prolong Shelf-Life of Fresh-Cut Apples. Postharvest Biology and Technology, 45, 254-264. http://dx.doi.org/10.1016/j.postharvbio.2007.01.017

[8] Srinivasa, P.C., Baskaran, R., Ramesh, M.N., Prashanth, K.V. and Tharanathan, R.N. (2002) Storage Studies of Mango Packed Using Biodegradable Chitosan Film. European Food Research Technology, 215, 504-508. http://dx.doi.org/10.1007/s00217-002-0591-1

[9] Chien, P., Sheu, F. and Yang, F. (2007) Effects of Edible Chitosan Coating on Quality and Shelf Life of Sliced Mango Fruit. Journal of Food Engineering, 78, 225-229. http://dx.doi.org/10.1016/j.jfoodeng.2005.09.022

[10] Dang, K.T.H., Singh, Z. and Swinny, E.E. (2008) Edible Coatings Influence Ripening, Quality, and Aroma Biosynthesis in Mango Fruit. Journal of Agricultural and Food Chemistry, 56, 1361-1370. http://dx.doi.org/10.1021/jf072208a

[11] Xu, S., Chen, X. and Sun, D. (2001) Preservation of Kiwifruit Coated with an Edible Film at Ambient Temperature. Journal of Food Engineering, 50, 211-216. http://dx.doi.org/10.1016/S0260-8774(01)00022-X

[12] Senna, M.M., Salmieri, S., El-Naggar, A., Safrany, A. and lacroix M. (2010) Improving the Compatibility of Zein/ Poly(Vinyl alcohol) Blends by Gamma Irradiation and Graft Copolymerization of Acrylic Acid. Journal of Agricultural and Food Chemistry, 58, 4470-4476. http://dx.doi.org/10.1021/jf904088y

[13] Senna, M.M.H., Abdel-Moneam, Y.K., Hussein, Y.A. and Alarifi, A. (2012) Effects of Electron Beam Irradiation on the Structure-Property Behavior of Blends Based on Low Density Polyethylene and Styrene-Ethylene-Butylene-Styrene-Block Copolymers. Journal of Applied Polymer Science, 125, 2384-2393. http://dx.doi.org/10.1002/app.36488

[14] Senna, M.M., El-Shahat, H., El-Naggar, A. (2011) Characterization of Gamma Irradiated Plasticized Starch/Poly(Vinyl Alcohol) (PLST/PVA) Blends and Their Application as Protected Edible Materials. Journal of Polymer Research, 18, 763-771. http://dx.doi.org/10.1007/s10965-010-9473-6

[15] Bajpai, A.K. and Shrivastava, J. (2005) In Vitro Enzymatic Degradation Kinetics of Polymeric Blends of Crosslinked Starch and Carboxymethyl Cellulose. Polymer International, 54, 1524-1536. http://dx.doi.org/10.1002/pi.1878

[16] Liu, P., Peng, J., Li, J. and Wu, J. (2005) Radiation Crosslinking of CMC-Na at Low Dose and Its Application as Substitute for Hydrogel. Radiation Physics and Chemistry, 72, 635-638. http://dx.doi.org/10.1016/j.radphyschem.2004.03.090

[17] Matsumura, S., Tomizawa. N., Toki, A., Nishikawa, K. and Toshima, K. (1999) Novel Poly(Vinyl Alcohol)-Degrading Enzyme and the Degradation Mechanism. Macromolecules, 23, 7753-7761. http://dx.doi.org/10.1021/ma990727b

[18] Moric, C.L.S., dos Passosa, N.A., Oliveirab, J.E., Mattosod, L.H.C., Moric, F.A., Carvalhoc, A.G., Fonsecac, A.S. and Tonolica, G.H.D. (2014) Electrospinning of Zein/Tannin Bio-Nanofibers. Industrial Crops and Products, 52, 298-304.

[19] Garcia, M., Martino, M. and Zaritzky, N. (2000) Microstructural Characterization of Plasticized Starch-Based Films. Starch-Stärke, 52, 118-124. http://dx.doi.org/10.1002/1521-379X(200006)52:4<118::AID-STAR118>3.0.CO;2-0

[20] Vasila, C. (2000) Handbook of Polyolefins. Marcel Dekker Inc., New York, 431. http://dx.doi.org/10.1201/9780203908716

[21] Radoslaw, A., Hiroshi, M., Naotsugu, N. and Fumio, Y. (2003) Crosslinking of Carboxy Methyl Cellulose of Various Degree of Substitution at High Concentration in Aqueous of Natural pH. Radiation Physics and Chemistry, 68, 771779 .

[22] Rezk, A.M.H., Senna, M.M. and Abdel-Bary, E.M. (1992) Gamma Radiation Stabilization of Polypropylene. Polymer International, 28, 265-270. http://dx.doi.org/10.1002/pi.4990280404

[23] Arvanitoyannis, I., Psomiadou, E., Nakayama, A., Aiba, S. and Yamamoto, N. (1997) Edible Films Made from Gelatin, Soluble Starch and Polyols, Part-III. Food Chemistry, 60, 593-604. http://dx.doi.org/10.1016/S0308-8146(97)00038-1

[24] Cuq, B., Gontard, N. and Guilbert, S. (1998) Proteins as Agricultural Polymers for Packaging Production. Cereal Chemistry, 75, 1-9. http://dx.doi.org/10.1094/CCHEM.1998.75.1.1 
[25] Hernandez-Izquierdo, V. and Krochta, M. (2008) Thermoplastic Processing of Proteins for Film Formation-A Review. Journal of Food Science, 73, 30-39. http://dx.doi.org/10.1111/j.1750-3841.2007.00636.x 